\title{
Economic determinants of total factor productivity growth: The Bayesian modelling averaging approach
}

\author{
Janusz Sobieraj, Dominik Metelski
}

\begin{abstract}
A B S T R A C T
Objective: : The objective of this article is to use the most recent national-level data (reflecting heterogeneity) to explore determinants of total factor productivity (TFP) growth.

Research Design \& Methods: The article examines the performance of a number of potential TFP growth determinants, relying on the Bayesian modelling analysis (BMA) methodology, which allows for isolating key regressors and assessing their actual contribution in relation to the phenomenon under study. As a scientific methodology, BMA is deeply rooted in statistical theory and directly results in posterior and predictive inferences. Moreover, BMA makes it easier to determine the relative impact of examined processes, while taking into account the uncertainty that accompanies the entire regressors' selection procedure (Raftery, Madigan, \& Hoeting, 1997; Hoeting, Madigan, Raftery, \& Volinsky, 1999; Sala-i-Martin, Doppelhofer, \& Miller, 2004).

Findings: We indicate a number of determinants driving TFP growth, e.g. inequality measured by the Gini coefficient, the growth of information and communications technology (ICT) assets, logistics performance, the quality of logistics services, and migration.

Implications \& Recommendations: We contribute to a more systematised knowledge of the determinants of TFP growth; the data shows that developed economies exhibit variable returns to scale (VRS). More importantly, there is an increasing contribution of ICT assets to economic growth and economies of scale, which is why whole economic systems exhibit increasing returns to scale (IRS). Some of the economic activity remains under-reported, meaning that economies of scale are even greater than the data reveals. In the era of globalisation, it becomes important to support digital technologies, address inequalities, create appropriate logistics infrastructure, and pay attention to mobility factors, e.g. labour migration.

Contribution \& Value Added: We conduct an overview of the literature so as to better understand the importance of TFP growth. Based on the literature, we identify a number of potential TFP growth determinants and examine their relevance and robustness using the BMA approach, which has become increasingly popular in recent years.

Article type: $\quad$ research article

JEL codes: $\quad$ O47, 050, 057, O30, N10

Received: 26 November $2020 \quad$ Revised: 26 May $2021 \quad$ Accepted: 29 May 2021
\end{abstract}

\section{Suggested citation:}

Sobieraj, J., \& Metelski, D. (2021). Economic determinants of total factor productivity growth: The Bayesian modelling averaging approach. Entrepreneurial Business and Economics Review, 9(4), 147-171. https://doi.org/10.15678/EBER.2021.090410

\section{INTRODUCTION}

The productivity of global economy has remained relatively low over the last decade. This phenomenon occurred despite significant technological progress, which has even begun to accelerate in recent years at a rapid pace (Watanabe $\&$ Ilmola, 2018). There is a particular innovation paradox in that large technological innovations do not necessarily lead to higher levels of economic productivity (Schwab, 2016; Sobieraj, 2019). A similar phenomenon already occurred in the past, shortly before the Great Depression of the 1930s. This is illustrated by the example of the United States of America, where 
between 1947 and 1983 labour productivity grew on average by $2.8 \%$ per year, while between 2000 and 2007 it rose by $2.6 \%$ per year, and between 2007 and 2014 only by $1.3 \%$ per year (Sobieraj, 2019). This marked decline in productivity growth - particularly pronounced in recent years - results from technological progress and economies of scale (Schwab, 2016; Watanabe \& Ilmola, 2018; Sobieraj, 2019). According to the US Bureau of Labour Statistics, the TFP growth rate in 2007-2014 was only $0.5 \%$, which is much lower compared to $1995-2007$. That number could easily be viewed as alarming, especially considering that it occurred at the time when the fifty largest US companies' accumulated assets totalled more than USD 1 trillion while interest rates for many years remained at almost zero (Schwab, 2016; Schwab \& Samans, 2016).

In general, TFP growth explains part of the output growth that is attributed to technological progress, which corresponds to the component growth not accounted for by capital or labour. Diewert and Fox (2008) go even further and present evidence showing that technical progress is generally irrelevant, suggesting that contrary to many previous results, economic growth is driven by increasing economies of scale rather than technical progress (Diewert \& Fox, 2008). However, as Danquah, MoralBenito, and Ouattara (2014) indicate, trying to explain such disparities is complicated because, on the one hand, TFP growth is difficult to measure empirically, while on the other hand, the uncertainty that accompanies the construction of scientific models makes it difficult to reach consensus on key determinants of productivity growth. In order to solve both of these problems, Danquah et al. (2014) point to a combination of non-parametric measures of TFP growth with Bayesian modelling averaging (BMA) technique. Moreover, Fernandez, Ley, and Steel (2001) employed the BMA method to shw how to model economic growth by taking into account the uncertainties typical for cross-sectional regression models. They argue that BMA gives an advantage over canonical regression models in that BMA averages across a large set of models for a given set of priors. Their predictive (out of the sample) results provide strong evidence supporting their respective arguments. By the same token, Fernandez et al. (2001) show which variables represent relevant regressors in explaining cross-sectional growth patterns. We believe that total factor productivity growth is about as important as the growth itself because the prosperity of individual nations depends largely on this factor. Furthermore, the importance of productivity for the whole economy is acknowledged by almost every economist. Some well-known economists such as Paul Krugman believe that the issue of productivity is pivotal for economic development of individual countries. More specifically, Krugman (1991) has repeatedly argued that while there are many important factors other than productivity, in the long run almost everything depends on productivity. In this respect, countries seeking to improve the quality of life of their citizens should focus almost entirely on increasing the productivity per capita levels (Krugman, 1991).

In view of the variety of economic considerations there is a number of factors that affect productivity growth measured by TFP growth. Among other things, these include a country's resource endowments, the growth of ICT assets (i.e. technology infrastructure), inequality, investment activity (reflected in the form of R\&D or total patent applications), fiscal policy, and FDIs, along with barriers to trade, logistics, and migration (Grossman \& Helpman, 1991; Baier, Dwyer, \& Tamura, 2006; Isaksson, 2007).

In this article, we conduct an in-depth analysis of a large set of TFP growth potential economic determinants and explore their role in explaining productivity growth. To examine their robustness in explaining TFP growth, we use the aforementioned BMA method, which allows for assessing the actual contribution of the proposed exogenous variables in relation to the phenomenon under study. As a scientific method, BMA is an extension of Bayesian inference methods, is deeply rooted in statistical theory, and directly results in posterior and predictive inferences. For example, BMA models are often used for the estimation and interpretation of dynamic stochastic general equilibrium (DSGE) models. They are very useful in explaining and predicting co-movements of aggregate time series over the business cycle (Sobieraj, Metelski, 2021). In other words, Bayesian model averaging provides a coherent and systematic mechanism accounting for model uncertainty (Fragoso, Bertoli, \& Louzada, 2018). Moreover, it simplifies the determination of relative impact on examined processes while taking into account the uncertainty that accompanies the entire selection procedure (Raftery et al., 1997; Hoeting et al., 1999; Sala-i-Martin et al., 2004). Over the last few years, BMA has gained in popularity in various types of studies. For the purpose of our study, we built a database 
based on various sources such as the Conference Board, WDI, and Eurostat, covering 41 countries and spanning the period of 1998-2015 (18 years in total).

The originality of our article lies in a thorough overview of the TFP growth determinants, the application of an interesting research method such as BMA, and the use of longitudinal data covering a wide variety of TFP growth potential regressors. However, some may argue that the topic of growth accounting and TFP growth research has already been thoroughly investigated. One might indicate the articles by Barro and Sala-i-Martin (1995), Sala-i-Martin et al. (2004), Danquah et al. (2014), and many others. However, many of these studies are now heavily outdated, and they address a very standard set of variables. Our assumption is that the globalisation processes of the last two decades have accelerated significantly, creating a number of different challenges that well-developed economies must now deal with, e.g. growing social inequality, the wealth gap, increased globalisation processes, associated factor mobilities (e.g. labour migration), industrial revolution 4.0, and the development of disruptive technologies, almost approaching an economic singularity. The result is arguably an increasing share of ICT in the creation of growth and economies of scale. Many new businesses almost exclusively rely on digital platforms and economies of scale, e.g. Amazon, Facebook, Uber, CoinBase. This may result in an even greater returns to scale. The relationship between changes in total factor productivity growth and changes in returns to scale and technologies was explored by Bauer (1990). However, that particular study was conducted more than 30 years ago. Our study includes a set of specific variables that have not been analysed before, e.g. ICT assets growth, migration, logistics performance and quality, air transport as passengers carried. More importantly, our study relies on more recent data. For example, the studies conducted by Barro and Sala-i-Martin (1995), Sala-i-Martin (2004), or even Danquah et al. (2014) - which are taken as certain benchmarks in the area of knowledge we are exploring - were all based on data dating back to the previous century.

The structure of our article is very straightforward. In the following part, we discuss some theoretical aspects concerning TFP growth. In the subsequent empirical part, we focus on the analytical aspects, data collection, and methodology. The article ends with conclusions.

\section{LITERATURE REVIEW}

The analysis of economic productivity constitutes one of the key issues in the framework of the research on growth and economic development, which is conducted at different levels of aggregation. Productivity reflects the value of goods and services per unit of resources utilised for their creation (i.e. labour, capital and other inputs), and is a key determinant of countries' wealth and standards of living (Krugman, 1990; Porter \& Ketels, 2003). According to Blinder and Baumol (1993), even small positive changes in the levels of productivity significantly translate into an increase in the wealth of a given society in the long term (Blinder \& Baumol, 1993). The same applies to interest rates which - like productivity - exert a significant impact on countries' wealth. Considering that the common low interest rate policy adopted by central banks around the world increases poverty of whole societies and causes social stratification - which manifests itself in the shrinkage of the middle class - the emphasis on productivity as a factor that mitigates the process of impoverishment of societies becomes even more important (Schwab, 2016). Blinder and Baumol (1993) argue that increasing productivity not only reduces poverty, but typically also improves the states' ability to finance education, health care, and environmental protection. Labour productivity can be expressed as the total value of production and services provided in relation to the total number of persons employed or total hours worked. To make a comparison of productivity among countries, one can use the ratio of a particular country's gross product value or gross value added to its number of employees or total hours worked (OECD, 2001). However, for the assessment of the performance of individual countries' economies, the TFP appears to be used more frequently (Danquah et al., 2014). It represents the total output of a country in relation to the total input factors utilised to its generation (Samuelson \& Nordhaus, 2012).

For years now, economists have been asking the very important question of how much productivity contributes to economic growth. Thus, there appeared attempts to link economic growth with physical and human capital per employee and to find out what part of this growth can be justified by technological 
or institutional changes and other factors (Grossman \& Helpman, 1991; Senhadji, 2000). From an economic viewpoint, we perceive an output growth as a function of capital: both physical and human. However, we cannot overlook the dynamic development of technology and the changes it causes in terms of conventional perception of productivity (Schwab, 2016; Watanabe \& Ilmola, 2018; Sobieraj, 2019).

The economic growth resulting from the growth of physical and human capital can be calculated based on certain assumptions about constant returns to scale and competitive factor markets. However, if we take the output growth rate calculated in this way and compare it with the actual growth rate, there will always be some deviations, which are caused by technological changes and other factors. Scientists try to identify these factors. For example, in addition to the aforementioned technological advancements, Baier et al. (2006) point to institutional differences, imperfections in competitive factor markets, instability of returns to scale, and a number of other factors. It is these differences or, rather, deviations from expected output under some specific assumptions that are referred to as the total factor productivity (TFP). We should mention here the theory of growth and the theoretical contribution made by Solow (1956) and Swan (1956), who are considered forerunners of the research on growth accounting. In fact, the literature sometimes calls TFP the Solow's residual (Burda \& Severgnini, 2010; Comin, 2010; Ten Raa \& Shestalova, 2011). In economics, the Solow's residual is the portion of an economy's output growth that cannot be attributed to the accumulation of capital and labour, which are perceived as conventional factors of production. In the same vein, the TFP concept was addressed by Abramovitz (1956), who studied economic growth in the USA and took a very broad time horizon (i.e. several decades long), eventually coming to the conclusion that $90 \%$ of the output growth was solely the result of TFP growth. Hence, the impact of productivity factors on economic growth and output growth appears to be of minor importance when compared to TFP growth. Similar findings were observed by Solow (1957), who studied the output growth in the USA in the first half of the twentieth century and came to the conclusion that the share of physical capital in this growth was only $12 \%$ while the rest could be attributed to the growth in TFP. In fact, the scientists who studied economic growth in later years confirmed prior findings observed by Abramovitz (1956) and Solow (1957), although in their studies the difference between physical and human capital and that of TFP growth was not as much pronounced as in those earlier studies (Kendrick, 1961; Jorgenson, Kuroda, \& Nishimizu, 1987; Angus, 1995; Klenow, 1997; Klenow \& Rodriguez-Clare, 1997; Jones, 1997; David, 2000; Denison, 2005). After reading all of the aforementioned authors, one may conclude that a very large part of economic expansion is dependent on TFP growth. Or at least such was the case in the past. Since TFP growth is extremely important for understanding economic growth and the creation of the wealth of nations, the objective of this article is to examine what really influences TFP growth by taking into account a large set of potential variables. However, the question arises why is it even necessary to repeatedly study TFP determinants? The reason is that the economic world is changing, so are the relationships between productivity factors, and therefore also the factors that determine the increase in production of individual nations. Finally, economic growth is obvious in some countries, despite a visible downward trend in TFP, as is the case in the United States.

In Figure 1, we can see that TFP growth typically tends to increase (in short-term) following the periods of major crises (e.g. during the recession of 2001-2002 and 2008-2009). However, the general trend remains downward, as shown by the regression line above (Figure 1). Watanabe and IImola (2018) notice that productivity of the global economy has declined during last decades and that it is now about half of its peak year in 1973. In this situation, it is evident that the companies attracting investors are technological and - more importantly-digital companies, which can improve traditional processes with high productivity increases. Moreover, as the recent acquisition activity in the digital market proves, the companies are investing their higher returns in addition to technologies such as artificial intelligence but in buying successful start-ups as well. Compared to earlier studies, Baier et al. (2006) show that when taking into account a larger pool of countries, TFP growth leads only to a small average output growth. According to their findings, the weighted average TFP growth rate for all countries is only $0.22 \%$ per year, which can be linked to a mere $14 \%$ increase in output growth per employee. These are estimates that differ significantly from those of previous scientist, who attributed more than half or even more of the output growth per worker to TFP growth. However, the study 
conducted by Baier et al. (2006) shows that an average change in TFP across 145 countries is actually negative and amounts to $-0.81 \%$ per year. This can be understood as meaning that if we randomly (i.e. with the same probability) select a country from the aforementioned pool of countries, we should expect a decrease in TFP of $-0.81 \%$ per year rather than a growth. Given that there is still intense technological growth, creative destruction, disruptive innovations, it is hard to understand such a decline (Schwab, 2016; Sobieraj, 2019). Baier et al. (2006) explain it by what they call institutional retrogression and by events of a destructive nature such as armed conflicts. However, if an ongoing, increasingly rapid technological progress does not bring about significant changes in productivity, further growth in the global economy could be seriously endangered. Therefore, we should address the question as to whether further rapid technological progress and innovations can reverse the negative trend in productivity decline in the global economy. There is no easy explanation to this question. Most innovative products and services developed already during the fourth industrial revolution have much higher functionality and quality (Sobieraj, 2019). They should also make the whole economy more efficient and productive, but so far, this has not proved to be the case (Schwab, 2016). However, as Sobieraj (2019) notices, we should bear in mind that the added value created by these innovative technologies is not always reflected in official statistics. This is due to the fact that many digital products and services are delivered and consumed beyond all recognition, i.e. out of the recorded data controls, which means that they are not even included in official statistics, e.g. services provided under the shared economy model (Schwab, 2016; Sobieraj, 2019). For example, the drivers working for Uber do not necessarily have to report about their activities to any competent authorities. The same applies to many other services that benefit from the advantages of digital economy, e.g. Airbnb or Blablacar. In turn, thanks to the blockchain technology, many transactional exchanges are - or may remain in the future - beyond any control of national governments (Sobieraj, 2019). According to economist Bradford Delong (2015), new digital technologies allow us to produce and consume much more efficiently today than economic indicators may reflect. We may only hope that in terms of efficiency and productivity, the reality looks much better than it is shown in the official statistics. According to Schwab (2016), the advancement of new technologies satisfies many consumer needs earlier unaddressed simply due to the lack of such technologies and appropriate business models such as the shared economy model (Schwab, 2016). Of course, this is beneficial to the global economy, but it distorts the productivity data of many national economies, which may seem less productive than they truly are (Sobieraj, 2019). Therefore, it is possible that the change in productivity growth, which we see in official statistics, is in fact not a decrease but an increase. However, new economic models (beyond official statistics) do not confirm such a state of affairs (Schwab, 2016).

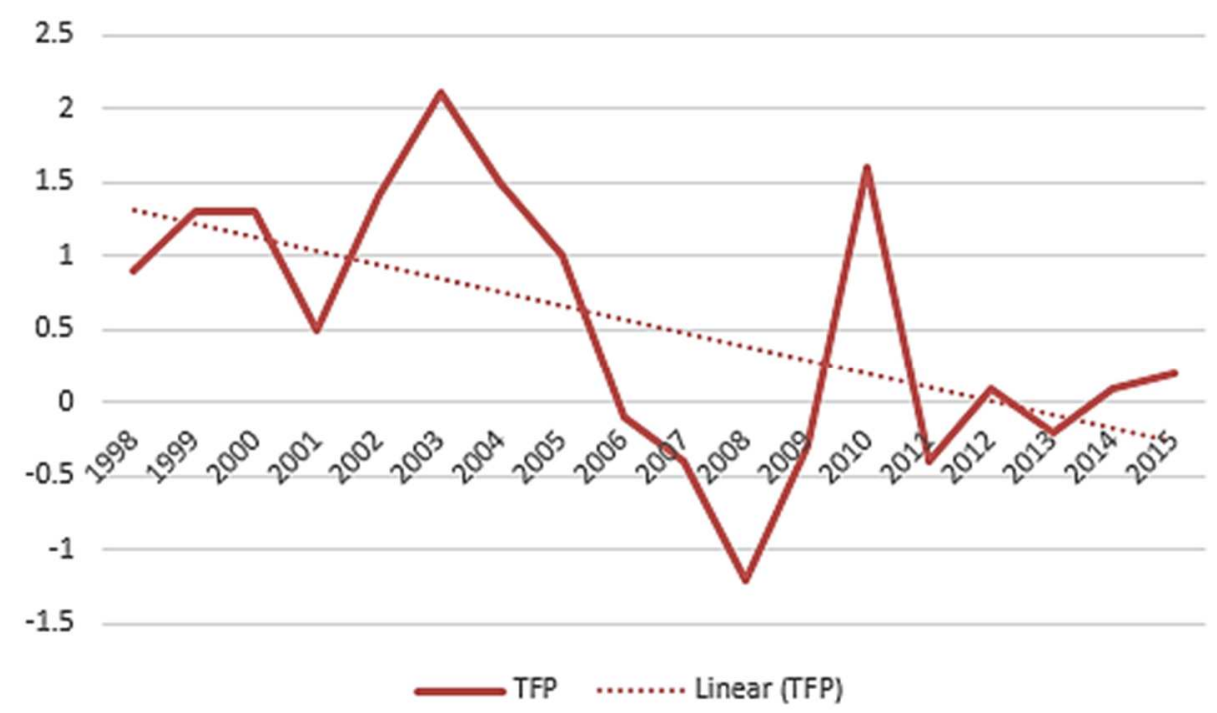

Figure 1. Total Productivity Factor for USA in 1998-2015

Source: own elaboration based on the Conference Board data. 
Interestingly, the very differences in economic patterns across countries show a much greater linkage to TFP changes than to changes in physical and human capital (Baier et al., 2006). This is important evidence which proves the purposefulness of conducting research on productivity growth measured by TFP growth, so as to understand and explain changes in economic conditions across countries. If understood properly, the measure of TFP may allow us to better understand the well-being of countries around the world. However, in order to fully understand TFP growth, we should do more than just look for its association with new technologies. Many potential factors must be explored. Although, in order to know which ones are worthy of interest, we must review the literature and collect what other authors have already established.

To identify and assess individual productivity determinants, researchers often rely on the neoclassical aggregate Cobb-Douglas-like production function (Cobb \& Douglas, 1928):

where:

$$
Y=F(K, L)=A K^{\alpha} L^{1-\alpha} \Rightarrow C R S
$$

$Y$ - is a stream of generated products and services (i.e. output), expressed as GDP or gross value added;

$Y>0$ - is the total factor productivity (TFP), $\mathrm{K}$ and $\mathrm{L}$ correspond respectively to the physical capital resources and labour inputs employed, i.e. the number of individuals employed or the total hours worked;

$\alpha$ - denotes the production flexibility in relation to capital expenditures (capital input);

$C R S$ - means that this type of aggregate production function (AFP) exhibits constant returns to scale (CRS), meaning that the elasticities of all inputs with respect to output sum up to one (AFP is relevant for both the theory of economic growth and empirical research on growth, e.g. in the context of growth accounting and development accounting; Osiewalski, Wróblewska, \& Makieła, 2020).

Based on the aforementioned Cobb-Douglas aggregate production function, it appears that productivity is dependent on the capital-to-labour ratio. It results from the accumulation of physical capital, but also from the total factor productivity $A$. The Cobb-Douglas production function indicates the capital accumulation and total factor productivity as two pivotal factors influencing the level and dynamics of labour productivity; in turn, the interpretation of total factor productivity is no longer as obvious as it might have seemed. The Cobb-Douglas aggregate production function with its constant returns to scale assumption is by far the most restrictive functional specification. Therefore, it should come as no surprise to anyone that all research based on the Cobb-Douglas function and Solow residuals, provide evidence showing a significant proportion of GDP growth associated with TFP growth. On the other hand, there are several research articles in which TFP is not regarded as a mere residual (Färe, Grosskopf, Norris, \& Zhang, 1994; Koop, Osiewalski, \& Steel, 1999; Benkovskis, Fadejeva, Stehrer, \& Wörz, 2012).

It should also be made clear that the idea behind such growth studies, i.e. those which rely on the aggregate production function - has received much criticism (Shaikh, 1974; Simon, 1979; Temple, 2006, Osiewalski, Wróblewska \& Makiela, 2020; Felipe \& McCombi, 2014). Osiewalski et al. (2020) note that while from a microeconomic level perspective production functions are well suited to describe the technologies of individual producers, an aggregation of physical capital, labour, and production itself is virtually impossible. There are many contradictions already at the theoretical level that actually preclude any relationship between aggregates (Fisher, 1969), which is due, among other things, to the very specific assumptions of such functions (Jones, 2005; Growiec, 2008, 2013). However, even assuming no microeconomic basis for the aggregate production function (APF), the concept still finds supporters who see its strengths in a well-defined mathematical relation, i.e. it is a local first-order approximation of any smooth production function expressed in terms of logs of inputs and outputs (Osiewalski et al., 2020). However, Osiewalski et al. (2020) indicate that a more popular form is the translog, which is a second-order local approximation.

The prevalence/popularity of the Cobb-Douglas function and its common application in empirical studies - despite the criticism mentioned above - are determined by its simplicity, historical considerations, and good data fit. The APF can by employed for international comparisons of economic growth 
(world technological frontier) and to show the main sources of economic growth through its decomposition (Koop et al., 1999, 2000; Makieła, 2014).

The APF is used to explain economic growth, productivity, and employment. However, this concept is extremely problematic and repeatedly criticised (Shaikh, 1974; Felipe \& McCombie, 2014; Temple, 2006; Osiewalski et al., 2020). Felipe and McCombie (2014) criticise the APF because the inputs and outputs used in it are linked through an accounting identity that relates the value added to the sum of wage costs and profits. In their view, a simple comparison of APF-based predictions with actual observations is not sufficient to determine whether the APF concept works. In other words, the restrictive conditions for a coherent aggregation of heterogeneous capital goods, different types of labour, and different productions can hardly be expected to come to life in the real world.

Total factor productivity by definition reflects all the factors affecting productivity, even though they are not directly factored in the production function. In this regard, Mankiw, Romer, and Weil (1992) point to the level of human capital, since it influences technological development, entrepreneurship, and creation of innovations leading to creative destructions and disruptive innovations (Mankiw et al., 1992; Sobieraj, 2019). The theory of endogenous growth contributes to a number of studies, which apart from human capital, indicate research and development (R\&D) activities as pivotal factors that influence economic growth (Romer, 1990; Grossman \& Helpman, 1991). According to the definition by the Organization for Economic Collaboration and Development (OECD), R\&D is defined as the activities involving creative work undertaken in a systematic manner so as to increase knowledge and the use of resources for new applications (Frascati, 2002). As it turns out, R\&D significantly impacts productivity since it is accountable for generating innovations and their subsequent transfer. It is also worth noting that there are empirical studies proving bidirectional complementarity between R\&D and human capital, which show their importance (Engelbrecht, 2002; Xu \& Wang, 1999; Frantzen, 2000; Crispolti \& Marconi, 2005; Bronzini \& Piselli, 2006). Moreover, other important factors that determine productivity include openness of the economy to capital investment measured by the level of FDI, competitiveness of the economy measured by the level of trade with other countries, along with the level of infrastructure (e.g. transport, logistics performance), and the overall conditions ensuring the freedom of doing business, e.g. all the factors that prove the quality of democracy in a given country (i.e. institutional, political, and cultural). Entrepreneurial freedom can be measured, for example, by the freedom index or doing business index. The role of FDI and trade in driving productivity growth is highlighted by Pietrucha and Żelazny (2020). In turn, Artige and Nicolini (2006) note that factors such as employment, capital levels, R\&D, and competitiveness determine productivity levels. They show that these factors influence both the productivity differentiation between regions (they studied regions in different European countries) and individual sectors of the economy (Artige \& Nicolini, 2006). By the same token, Decker, Thompson, and Wohar (2009) conducted a study on the comparison of productivity in different states of America so as to identify inter-sectoral specialisation, education level, infrastructure, and population density as the basic determinants of productivity. In turn, in their study on productivity in various Italian regions, Bronzini and Piselli (2006) identify the level of human capital, R\&D expenditure, and the quality of public infrastructure as key factors that influence productivity levels. Their research shows that out of all factors taken into account in their model, human capital played the most important role in shaping productivity levels. They use Granger's bidirectional causality concept, thus also indicating the direction of the interaction between individual variables, e.g. they prove Granger's causality for human capital, R\&D, productivity, and the level of infrastructure and productivity; although they do not find causality in the opposite direction. On the other hand, Di Giacinto and Nuzzo (2005) identify human capital, R\&D expenditure, public infrastructure level, public institutions functioning, and the level of financial markets development as key variables that affect productivity (Di Giacinto \& Nuzzo, 2005). Moreover, it turns out that globalisation and the accompanying increase in international trade can have a significant impact on productivity. For example, Hung, Salomon, and Sowerby (2004) studied the relationship between foreign trade and productivity to argue that trade could affect domestic productivity through economies-of-scale, competition, reallocation, and spillover effects. Furthermore, Sequeira, Santos, and Ferreira-Lopes (2017) criticise the general lack of empirical research on the causal link between human capital, technology, trade, and inequality. In the same vein, Espoir and Ngepah (2020) 
examine whether the growing inequality in income/wages increases total factor productivity. Their research provides evidence on positive spatial interactions with regards to the impact of income inequality on total factor productivity. They show that the estimated direct impact of income inequality on total factor productivity at regional level is negative and statistically significant, although on the other hand, there is also an indirect impact, which in turn, is positive.

When analysing TFP growth, we should also consider the mobility factors viewed as substitutes, which was first raised by Heckscher and Ohlin many years ago, and then revisited in literature by other authors (Markusen, 1983; Schiff, 1994; Metelski \& Mihi-Ramirez, 2015). Therefore, given the growing importance of mobility factors in modern economies, we also propose to include FDI, trade, and migration (measured by the Crude Rate of Net Migration) in the set of regressors that can potentially affect TFP growth.

To sum up, the literature argues that the following factors influence productivity:

- the level of human capital that represents the quality of labour in terms of measurement (Grossman \& Helpman, 1991; Di Giacinto \& Nuzzo, 2005; Bronzini \& Piselli, 2006; Fukao \& Miyagawa, 2007; Manuelli \& Seshadri, 2014);

- capital's share (Parente \& Prescott, 2002);

- ICT investments and the complementary factors (O'Mahony \& Vecchi, 2003; Castiglione \& Infante, 2013);

- technological progress as primary driving force of productivity growth (Hamit-Haggar, 2011);

- R\&D project activities (Di Giacinto \& Nuzzo, 2005; Bronzini \& Piselli, 2006);

- innovations resulting from R\&D;

- the level of competitiveness (trade- as well as freedom-related);

- the level of education (Bronzini \& Piselli, 2006; Artige \& Nicolini, 2006);

- the openness of the economy to capital investments, and the transfer of knowledge captured by FDI flows (Grossman \& Helpman, 1991; Pietrucha \& Żelazny, 2020; Makieła, Wojciechowski, \& Wach, 2021). FDI conclusively transmits to growth via input change yet Makieła and Ouattara (2018) notice that statistical evidence lacks to support transmission via the TFP channel;

- openness towards trade (Hung et al., 2004; Danquah et al., 2014; Jorgenson \& Vu, 2018);

- transportation infrastructure (Liu, Wu, \& Liu, 2010);

- infrastructure and machinery also known as non-ICT (Bronzini \& Piselli, 2006; Decker et al., 2009);

- quality of labour infput (Manuelli \& Seshadri, 2014);

- inequality (Sequeira et al. 2017; Espoir \& Ngepah, 2020).

More than two decades ago, Prescott (1998) sought to explain the large differences in income between countries, relying on the theory of total factor productivity. He wondered whether the differences in capital per employee could account for the huge differences observed in production per employee. Eventually he came to the conclusion that such a link is impossible, and that factoring in intangible capital does not make from the model of neoclassical growth a theory explaining international income differences. According to Prectott, only if an investment in intangible capital corresponds to GDP by its scale, differences in saving rates may have significant implications for the output per employee. Moreover, the same applies to the models that take into account human capital. Such models fail for similar reasons. For differences in the rates of investment in human capital to be significant, the fraction of time allocated to strengthening human capital must be considerable enough. The neoclassical model of economic growth takes into account differences between countries only if total factor productivity differs from country to country. Prescott (1998) perceived differences in total factor productivity in the context of a resistance to the adoption of new technologies and the effective use of the newest technologies; according to him, this resistance largely depends on the political arrangements agreed by a society. It can be overcome, depending on the country, by what Mokyr (1990) described as technological creativity.

Some economists prefer to use the term "multifactor productivity" (MFP) instead of total factor productivity. The reason for this is that it is almost impossible to determine all the inputs that explain the residual component of the output growth not directly linked to production inputs. Ayres and Warr 
(2005) indicate that one such input may be e.g. energy conversion efficiency, but it can also be public infrastructure or some attributes related to labour force that are rarely considered (Schreyer, 2001; Diewert \& Nakamura, 2007; Shackleton, 2013). Sickles and Zelenyuk (2019) define total factor productivity as a proportion of an aggregated production in relation to aggregated inputs. On the other hand, Comin (2010) argues that TFP reflects a fraction of output growth that cannot be attributed to labour and capital inputs utilised for production purposes. In this regard, Comin (2010) makes some simplification in terms of production technology. Measured in conventional terms, TFP represents the ratio of the production to the weighted average labour and capital inputs. According to Gordon (2017), the standard share of labour and capital is 0.7 in the case of the former and 0.3 in the latter. Comin (2010) also notes that TFP is a measure of economic efficiency that helps to understand per capita income differences between countries. Technological growth and efficiency performance are often highlighted as the two largest components of TFP. Nonetheless, new technologies have such an important function that they are usually accompanied by positive externalities and creative destructions or disruptive innovations, thereby fueling economic growth (Bower \& Christensen, 1995; Christensen \& Overdorf, 2000). Moreover, TFP is one of the factors that - apart from human and physical capital and labour input - is associated with economic growth. In classical terms, production growth is explained by the accumulation of production factors (i.e. labour and capital inputs). However, it turns out that part of the total growth of domestic production is also attributable to a residual component that cannot be linked in any way to those conventional production inputs (i.e., labour and capital). Total factor productivity is precisely the sought-after residual component that cannot be measured directly yet constitutes certain residual value that affects the growth of total production; but in itself, it is not directly linked to labour and capital inputs. On the other hand, Natividad (2014) demonstrates that TFP is positively associated with business-to-business integration. The higher the integration, the higher the productivity measured by TFP. In turn, Easterly and Levine (2002) find that in an average country, TFP is responsible for about $60 \%$ of production growth per worker. Moreover, Manuelli and Seshadri (2014) conducted a study on human capital to show that when analysing TFP, the quality of labour must be taken into account besides labour input. For example, school education can be employed as a proxy indicator for the quality of labour. The number of years of schooling does not address intra-country differences. Upon re-evaluation in this regard, it becomes clear that TFP's contribution is lower than scholars originally thought. However, TFP is criticised for the lack of significant units of measurement (Barnett, 2004). The notion of TFP seems to be only a modelling artifact, whereas in the formula of the above-presented CobbDouglas function, the $A$ term has no simple economic interpretation. In fact, there is a lack of statistical evidence showing unit-level measurement of productivity levels as TFP, and what we can rely on are only non-unit-level indicators of output and input growth, including residual value.

We should mention here the article by Fernald (2014) who enumerates a number of relatively high-quality sources of aggregate TFP, including the multifactor productivity measures released by the Bureau of Labor Statistics (BLS), various measures produced by Dale Jorgenson and collaborators, and the EU KLEMS project. Some important knowledge of the productivity measured by TFP is provided in the Jorgenson and Vu study (2018), who point to the example of Singapore, where TFP growth is extremely low (i.e. 0.5-0.6 per cent) in relation to its extraordinary output growth. In fact, Jorgenson and $\mathrm{Vu}$ (2018) study shows that low TFP growth can go hand in hand with high economic growth, and the causes of low productivity growth can be associated with factors such as the size of the economy, its vulnerability to various types of shocks and turmoil, the size of domestic market (i.e. this particularly refers to small countries), and the share of exports in GDP (i.e. the economy's dependence on trade). Danquah et al.'s (2014) study shows that the strongest determinants of the TFP growth are time-invariance, unobserved heterogeneity, and openness towards trade. Moreover, they indicate the change in efficiency (i.e. catching up) and technological advancement as two important components of TFP. Moreover, Fukao and Miyagawa (2007) notice that there is a positive correlation between ICT capital service input growth and TFP growth across countries.

Osiewalski et al. (2020) seek to find an empirical substantiation of APF within the framework of modern dynamic econometrics; to this end, they used annual data on total output and two factor aggregates. They capture such dynamics by modelling a three-variable, non-stationary time series, using VAR models 
and exploring with them Cobb-Douglas-type relationships in the context of parameter variation and VAR representations in terms of conditional and marginal models for output and inputs. These authors also investigate whether APF is a co-integration type relationship, i.e. one that shows a relationship between aggregate outputs and aggregate inputs. However, their results did not confirm any empirical validity of an APF-type relationship in modelling annual inputs and outputs for individual economies.

Makieła (2014) analyses productivity in European countries, USA, Japan, and Switzerland. More specifically, by conducting a Bayesian stochastic frontier analysis and a two-stage structural decomposition of output growth, the authors shows the impacts on economic development of capital accumulation, labour growth, technical progress, and technical efficiency change. Makieła and Ouattara (2018) scrutinse transmission channels of FDI on economic growth. Their results reveal that FDI affects growth through input factor accumulation but not through the TFP growth channel.

Makieła, Wojciechowski, and Wach (2021) study the impact of foreign direct investment on economic growth and productivity in the sectors of the Visegrad Group a decade after their accession to the EU. They rely on a generalized random-effects model with a variable efficiency distribution. Their results show that FDI positively impacts economic growth and productivity - whose efficiency depends, among other things, on the technology gap between the host and home economies - while one of the sources of this positive impact is seen in the higher efficiency component of TFP.

The truth is that productivity allows to better understand the level of resources in each country and, more importantly, to find an answer as to how efficiently and effectively these resources are exploited. Therefore, in order to find out which factors determine the existence of disparities in the levels of development of individual countries and in general, we must take into account the key determinants of productivity (Jarmołowicz \& Kuźmar, 2014). Based on the above overview of prior studies and some theoretical considerations, we propose to verify the following selective research hypotheses:

H1: Greater income inequality measured by the Gini coefficient shows strong association with TFP growth.

H2: Growth of ICT assets is an important determinant of TFP growth.

H3: The number of researchers in R\&D is an important determinant of TFP growth.

H4: Logistics performance and quality of logistics services are important determinants of TFP growth.

H5: Migration - as a substitute of foreign direct investments (FDI) and Trade (TRADE) - drives TFP growth.

H6: The number of air transport as carried passengers at national levels is an important determinant of TFP growth.

\section{MATERIAL AND METHODS}

In this section, we describe our empirical study that applied the same methodological approach as described in Sala-i-Martin (1997) and Fernandez et al. (2001). We covered 41 countries (i.e. 37 OECD countries plus Romania, Russia, Croatia, and Cyprus), for which TFP growth is computed over the period of 1998-2015. We obtained our data set from the Conference Board, World Bank (WDI), and Eurostat databases. Table 1 and Table 2 specify the variables we used. The data covered 18 yearly observations for 22 selected variables. The full list of sources is showed and characetrised in Table 1.

Our model employed the Bayesian model sampling (BMS) function described by Zeugner and Feldkircher (2015), which implements Bayesian modelling averaging (BMA) for linear regression models. Let us mention that BMS allows for different priors structures, including binomial-beta prior and the "hyper-g" specification for Zellner's g-prior. Furthermore, it allows researchers to specify their own model priors, setting the prior inclusion probabilities at one's own discretion. 
Table 1. List of variables used in the analysis

\begin{tabular}{|c|c|c|}
\hline No. & Variable name & Description \\
\hline$y_{t}$ & Total factor productivity growth & $\begin{array}{l}\text { Growth of total factor productivity, which is GDP growth (log change) mi- } \\
\text { nus the sum of the contribution of labor quantity to GDP growth, the con- } \\
\text { tribution of labor quality to GDP growth, and the contribution of total } \\
\text { capital services to GDP growth }\end{array}$ \\
\hline$X_{1}$ & Growth of ICT assets & Growth of services provided by ICT assets \\
\hline$X_{2}$ & Human capital growth & Growth of labor quality \\
\hline$X_{3}$ & Current education expenditure & Total (\% of total expenditure in public institutions) \\
\hline$X_{4}$ & $\begin{array}{l}\text { Government expenditure on ed- } \\
\text { ucation }\end{array}$ & Total (\% of government expenditure) \\
\hline$X_{5}$ & School enrollment, tertiary & School enrollment, tertiary (\% gross) \\
\hline$X_{6}$ & Transport services imports & $\%$ of commercial service imports \\
\hline$X_{7}$ & Transport services exports & $\%$ of commercial service exports \\
\hline$X_{8}$ & Air transport & Air transport, passengers carried \\
\hline$X_{9}$ & New business density & New registrations per 1000 people ages 15-64 \\
\hline$X_{10}$ & R\&D expenditure & Research and development expenditure as \% of GDP \\
\hline$X_{11}$ & Researchers in R\&D & Number of researchers engaged in R\&D projects (per million people) \\
\hline$X_{12}$ & Technicians in R\&D & Number of technicians engaged in R\&D projects (per million people) \\
\hline$X_{13}$ & Total patent applications & $\begin{array}{l}\text { Patent applications are global patent applications filed under the procedure } \\
\text { provided for in the Patent Cooperation Treaty or at a national patent office } \\
\text { to obtain exclusive rights to an invention, product, or process that provides } \\
\text { a new mode of operation or a new technical solution to a problem. }\end{array}$ \\
\hline$X_{14}$ & Trademark applications & Trademark applications, total \\
\hline$X_{15}$ & $\begin{array}{l}\text { Quality of trade and transport- } \\
\text { related infrastructure }\end{array}$ & $\begin{array}{l}\text { Logistics performance index (transport). Quality of trade and transport- } \\
\text { related infrastructure (1=low to } 5=\text { high) }\end{array}$ \\
\hline$X_{16}$ & Trade & Trade (\% of GDP) \\
\hline$X_{17}$ & $\begin{array}{l}\text { Foreign direct investment, net } \\
\text { inflows }(\% \text { of GDP) }\end{array}$ & $\begin{array}{l}\text { Foreign direct investments (FDI) are the net inflows of investment to ac- } \\
\text { quire a lasting management interest ( } 10 \% \text { or more of voting stock) in an } \\
\text { enterprise operating in an economy other than that of the investor }\end{array}$ \\
\hline$X_{18}$ & Crude rate of net migration & $\begin{array}{l}\text { The crude rate of net migration is equal to the difference between the } \\
\text { crude rate of increase and the crude rate of natural increase, i.e. net mi- } \\
\text { gration is considered as the part of population change not attributable to } \\
\text { births and deaths. }\end{array}$ \\
\hline$X_{19}$ & $\begin{array}{l}\text { Competence and quality of lo- } \\
\text { gistics services (quality) }\end{array}$ & $\begin{array}{l}\text { Logistics performance index: competence and quality of logistics services } \\
\text { (1=low to } 5=\text { high) }\end{array}$ \\
\hline$X_{20}$ & Quality of port infrastructure & $\begin{array}{l}\text { Quality of port infrastructure, WEF ( } 1=\text { extremely underdeveloped to } \\
7=\text { well developed and efficient by international standards) }\end{array}$ \\
\hline$X_{21}$ & $\begin{array}{l}\text { Logistics performance index } \\
\text { (Overall) }\end{array}$ & Overall performance (1=low to $5=$ high) \\
\hline$X_{22}$ & Gini coefficient & $\begin{array}{l}\text { Gini coefficient measures the extent to which the distribution of income } \\
\text { (or, in some cases, consumption expenditure) among individuals or house- } \\
\text { holds within an economy deviates from a perfectly equal distribution }\end{array}$ \\
\hline
\end{tabular}

Source: own study.

Bayesian modelling averaging has an advantage over other econometric techniques in that it consistently and systematically - and more readily - deals with model uncertainty (Fragoso et al., 2018). This method employs Bayesian inference to select the right model, which solves the problem of combined estimation and forecasting. Moreover, BMA adopts a relatively simple criterion for model selection, although the use of this methodology is not necessarily straightforward, and the choice of the final model based on BMA often depends on various aspects and the resulting assumptions and situational choices. Thus, BMA allows one to solve the problem of uncertainty associated with determining the appropriate choice of model specification. The problem arises when there are too many potential exogenous explanatory regressors. In other words, BMA is a method that indicates which explanatory 
variables should be included in a canonical linear regression model, when there is a choice of many alternative models and potential variables contained in a matrix $X$ :

$$
y=\alpha_{\gamma}+X_{\gamma} \beta_{\gamma}+\varepsilon ., \varepsilon \sim N\left(0, \sigma^{2} I\right)
$$

where:

$y$ - is the dependent variable (i.e. TFP growth);

$\alpha_{\gamma}$ - is a constant;

$\beta_{\gamma}$ - are the coefficients;

$\varepsilon$ - is a normal IID error term with variance $\sigma^{2}$.

When it comes to the number of potential choices there are as many as $X_{\gamma} \in\{X\}$ variables that a researcher can choose from. Suppose that matrix $X$ contains $K$ potential explanatory variables. This means that there are $2^{K}$ potential sets of explanatory variables and thus also $2^{K}$ models. The choice with regards to specifications may have a significant impact on the estimated values of parameters for individual variables. On the basis of a single specification of a linear regression model encompassing all variables, the inference cannot be very reliable, and with a small number of observations, it is ineffective or even impracticable. The BMA method solves this problem since it takes into account all possible combinations of $\{X\}$ and establishes a weighted average for all of them. The model weights considered in the averaging method are determined based on posterior probabilities, what can be described with the Bayes theorem (Zeugner \& Feldkircher, 2015):

$$
p\left(M_{\gamma} \mid y, X\right)=\frac{p\left(y \mid M_{\gamma}, X\right) p\left(M_{\gamma}\right)}{p(y \mid X)}=\frac{p\left(y \mid M_{\gamma}, X\right) p\left(M_{\gamma}\right)}{\sum_{s=1}^{2^{K}} p\left(y \mid M_{s}, X\right) p\left(M_{S}\right)}
$$

in which $p(y \mid X)$ is the probability that is constant for all models and therefore can be perceived as a multiplier term. In turn, $p\left(M_{\gamma} \mid y, X\right)$ is the posterior model probability (denoted as PMP), which is proportional to the marginal probability $p\left(y \mid M_{\gamma}, X\right)$ (the probability resulting from the model $M_{\gamma}$ ) multiplied by $p\left(M_{\gamma}\right)$, i.e. the prior model probability. The latter indicates the assumptions made by the researcher about the model $M_{\gamma}$ based on one's subjective preferences. The procedure of renormalisation subsequently yields certain posterior model probabilities and model-weighted posterior distributions for every $\beta$ coefficient. This can be expressed with the following formula:

$$
p(\theta \mid y, X)=\sum_{\gamma=1}^{2^{K}} p\left(\theta \mid M_{\gamma}, y, X\right) \frac{p\left(M_{\gamma} \mid X, y\right) p\left(M_{\gamma}\right)}{\sum_{s=1}^{2^{K}} p\left(M_{s} \mid y, X\right) p\left(M_{s}\right)}
$$

As a general rule, before estimating BMA parameters, one must make certain assumptions about the model prior $p\left(M_{\gamma}\right)$. In the case when we do not have adequate knowledge about specific model parameters, the most common assumption - also made by us for the purposes of our study - is to assume the uniform probability of these distributions.

The adoption of a specific estimation framework impacts the results obtained, i.e. posterior distributions, also known as posteriors $p\left(\theta \mid M_{\gamma}, y, X\right)$. In our study, we relied on a linear "Bayesian regression" model with the g-prior developed by Zelnner (1986). The Zelnner's g is an objective prior for the coefficients of a multiple regression. The posterior distribution of the coefficients follows a $t$-distribution with expected value $E\left(\beta_{\gamma} \mid y, X, g, M_{\gamma}=\frac{g}{1+g} \hat{\beta}_{\gamma}\right)$, with Zellner's g and $\widehat{\beta}_{\gamma}$ denoting the standard OLS estimator.

In essence, the empirical part of our study was based on the model described by (3). Therefore, we made certain assumptions, i.e. constant $\alpha_{\gamma}$, error variance $\sigma^{2}$, error distribution described $\varepsilon \sim N\left(0, \sigma^{2} I\right)$, priors that are evenly distributed in their domain $p\left(\alpha_{\gamma}\right) \propto 1$ and $p(\sigma) \propto \sigma^{-1}$. Naturally, we do not know what these distributions actually are, and therefore their priors are improper (they integrate to infinity and they are $\sigma$-finite measures).

Please note that the assumed prior for the errors' standard deviations $\sigma$ is not uniform. This prior is uniform for $\ln (\sigma)$. And from this assumption, we can obtain the prior for $\sigma$ in the assumed form (i.e. proportional to $1 / \sigma$ ). Such prior follows Jeffrey's rule, and it is often called Jaffrey's prior. 
Similarly, we made certain assumptions about the regression coefficients. We assumed that they can be described by a normal distribution with zero mean and a variance, which follows the Zellner's $g$-prior given by: $g \sigma^{2}\left(X_{\gamma}^{T} X_{\gamma}\right)^{-1}, \beta_{\gamma} \mid g \sim N\left(0, g \sigma^{2}\left(X_{\gamma}^{T} X_{\gamma}\right)^{-1}\right)$.

In the case of regression coefficients, the assumption that their mean is zero reflected our lack of knowledge about their sign, while variance and covariance addressed the structure of data $X_{\gamma}$. In turn, in so far as our belief about the parameters was concerned, it was reflected by the priors' dispersion. The expected value of the coefficients is a convex combination of that zero mean and the OLS estimator. In turn, the size of the g-priors reflects the researcher's belief about the coefficients themselves. As g increases, so does the variance of coefficients, which in turn reflects one's drop of confidence in the assumptions made about the aforementioned mean (which is assumed to be zero, due to the lack of an a priori knowledge about the coefficients). In general, the more conservative the $g$-values taken in the assumptions, the greater the relevance of the priors. For smaller values of $g$, the expected value of coefficients is more likely to converge to the zero mean of the prior. When $g$-prior increases, the coefficient estimator approaches the OLS estimator.Thus, taking a specific $g$-prior assumption affects the posterior variance $\beta_{\gamma}$ of the coefficients:

$$
\operatorname{COV}\left(\beta_{\gamma} \mid y, X, g, M_{\gamma}\right)=\frac{(y-\bar{y})^{T}(y-\bar{y})}{N-3} \frac{g}{1+g}\left(1-\frac{g}{1+g} R_{\gamma}^{2}\right)\left(X_{\gamma}^{T} X_{\gamma}\right)^{-1}
$$

From the above formula we can see that the posterior covariance differs from the covariance of the OLS estimator in that it takes into account the $g$-prior. In turn, the marginal likelihood $p\left(y \mid M_{\gamma}, y, X\right)$, resulting from the prior framework, depends on the model size $k_{\gamma}$, which can be expressed in the following way:

$$
p\left(y \mid M_{\gamma}, X, g\right) \propto(y-\bar{y})^{T}(y-\bar{y})^{-\frac{N-1}{2}}(1+g)^{-\frac{k \gamma}{2}}\left(1-\frac{g}{1+g}\right)^{-\frac{N-1}{2}}
$$

\section{RESULTS AND DISCUSSION}

Given a number of production functions (including Cobb-Douglas production function, partially parameterised Cobb-Douglas and others), when analysing TFP growth it is beneficial to check whether CRS restriction holds, i.e. whether or not these functions exhibit increasing returns to scale (IRS), decreasing returns to scale (DRS), or constant returns to scale (CRS). This is important because CRS is a restriction that can significantly decrease a model fit and thereby also exert an impact on the model's residuals (i.e. the ones reflected in equation 1 above), very likely making them larger. In other words, returns to scale shows how much the output changes given a proportional change in all inputs, in which all inputs change by the same factor (i.e. returns: how much output changes; scale: given a constant proportional change in all the factors.). This can be expressed in the following manner:

$$
F(2 K, 2 L)=A(2 K)^{\alpha}(2 L)^{1-\alpha} \begin{cases}<2 Y, & \Rightarrow \text { Decreasing Returns to Scale } \\ =2 Y, & \Rightarrow \text { Constant Returns to Scale } \\ >2 Y, & \Rightarrow \text { Increasing Returns to Scale }\end{cases}
$$

Typically, to test a variety of model restrictions, we can use the F-test, which is most commonly used to test for joint significance of a group of variables. However, F-test can also be used to test if CRS restriction applies, whereby a proportional increase in all inputs yields a proportional increase in the output. One example is the Cobb-Douglas production function. A logarithmic representation of the production function (similar to equation 1 ) can be expressed in the following form (this is only a simplification in which $1-\alpha$ parameter is replaced by $\alpha_{2}$ ):

$$
\log y_{t}=\alpha_{0}+\alpha_{1} \log k_{t}+\alpha_{2} \log l_{t}+u_{t}
$$

We can assume that under the null $H_{0}: \alpha_{1}+\alpha_{2}=1$, the CRS restriction holds, whereas rejection of the null is indicative of a variable returns to scale $\left(H_{1}: \alpha_{1}+\alpha_{2} \neq 1\right)$. Consequently, by regressing output on labour and capital inputs (all data taken from the Conference Board Database) and collecting RSS values from both restricted and unrestricted regression specifications, we came up with the $\mathrm{F}$ test results. F-statistic $\left(F=\frac{\left(R S S_{0}-R S S\right) / p}{R S S /(n-p-1)}\right)$ was equal to 0.8459 on 2 and $581 \mathrm{DF}$ (154 
observations were deleted due to missingness), with $p$-value $=0.4297$. Since F-statistic was greater than $F_{\text {critical }}$ value, we rejected the null hypothesis of constant returns to scale $\left(\alpha_{1}+\alpha_{2}=1\right)$, concluding that the unrestricted model is best.

We used a specific set of variables to estimate the BMA model. The TFP growth was our endogenous variable in that model. To visualise the characteristics of the data we provide its description in Table 2.

Table 2. Variables characteristics (data description)

\begin{tabular}{|c|c|c|c|c|c|c|c|c|c|c|}
\hline Var & Var Name & $\mathbf{n}$ & Mean & sd & Med. & Min & Max & Skew & Kurtos. & se \\
\hline$y_{t}$ & Total factor productivi & 738 & . & 3.33 & .38 & -18.13 & 19.43 & -0.21 & 1.10 & 0.12 \\
\hline$X_{1}$ & Growth of ICT assets & 624 & 17.33 & 9.84 & 15.23 & -9.11 & 54.88 & 0.83 & 0.81 & 0.39 \\
\hline$X_{2}$ & Human capital growth & 684 & 0.53 & 0.8 & 0.42 & -5.15 & 7.23 & .78 & 14.03 & 0.03 \\
\hline$X_{3}$ & Current education expend & 492 & 91.63 & 4.03 & 92.04 & 63.95 & 100 & -1.48 & 5.61 & 0.18 \\
\hline$X_{4}$ & Government expenditure on education & 569 & 12.3 & 2.73 & 12.07 & 5.98 & 22.27 & & & 0.11 \\
\hline$X_{5}$ & School enrollment, tertiary & 663 & 3.99 & 0.4 & 4.07 & 2.2 & 4.81 & -1.48 & 7 & 0.02 \\
\hline$X_{6}$ & Transport services exports & 661 & 27.25 & 15.3 & 24.42 & 0.14 & 71.74 & 0.62 & -0.33 & 0.6 \\
\hline$X_{7}$ & Transport services imports & 661 & 27.53 & 12.9 & 24.87 & 0.29 & 62.83 & 0.48 & & 0.51 \\
\hline$X_{8}$ & Air transport passenge & 695 & 2.76 & 0.13 & 2.76 & 2.29 & 2.98 & -0.45 & & 0 \\
\hline$X_{9}$ & New business density & 374 & 5.12 & 4.86 & 3.96 & 0.28 & 39.04 & 2.69 & 10.75 & 0.25 \\
\hline$X_{10}$ & R \& D expenditure (\% of $G$ & 669 & 1.27 & 0.86 & 1.03 & 0.02 & 3.91 & 0.91 & 0.02 & 0.03 \\
\hline$X_{11}$ & Researchers in R\&D (per & & 7.71 & 0.73 & 7.82 & & & & & 0.03 \\
\hline$X_{12}$ & Technicians in R\&D & 467 & 6.36 & 0.96 & 6.35 & 3.56 & 8.23 & -0.57 & 0.31 & 0.04 \\
\hline$X_{13}$ & Total patent applications & 688 & 6.47 & 2.00 & 6.57 & 0.69 & 10.85 & -0.1 & -0.07 & 0.08 \\
\hline$X_{14}$ & Trademark ap & 682 & 9.28 & 1.07 & 9.16 & 6.56 & 11.67 & 0.29 & & 0.04 \\
\hline$X_{15}$ & Quality of trade and transport & 159 & 3.23 & 0.66 & 3.17 & 1.78 & 4.34 & -0.01 & -1.22 & 0.05 \\
\hline$X_{16}$ & Trade (\% of GDP) & 738 & 4.52 & 0.44 & 4.47 & 3.11 & 6.01 & 0.58 & 0.45 & 0.02 \\
\hline$X_{17}$ & FDI, net inflows (\% of GDP) & 582 & -0.24 & 0.64 & -0.05 & -4.37 & 0.52 & -2.62 & 10.02 & 0.03 \\
\hline$X_{18}$ & Crude rate of net migration & 725 & 1.39 & 6.6 & 1.2 & -46.8 & 34 & -0.57 & 7.77 & 0.25 \\
\hline$X_{19}$ & Competence and quality of logistics services & 159 & 3.27 & 0.58 & 3.23 & 2 & 4.32 & -0.08 & -1.06 & 0.05 \\
\hline$X_{20}$ & Quality of port infrastructure & 356 & 4.64 & 1.19 & 4.73 & 1.5 & 6.8 & -0.34 & -0.54 & 0.06 \\
\hline$X_{21}$ & Logistics performance index & 159 & 3.31 & 0.53 & 3.26 & 2.08 & 4.18 & -0.16 & -1.09 & 0.04 \\
\hline$X_{22}$ & Gini coefficient & 636 & 2.6 & 4.38 & 2.74 & -25.72 & 19.8 & -0.7 & 4.23 & 0.17 \\
\hline
\end{tabular}

Source: own elaboration in R-studio.

We modelled the TFP growth results with the use of linear regression as follows:

where:

$$
y_{i}=\beta_{0}+\beta_{m}^{T} X_{i}^{m}+u_{i}
$$

$X_{i}^{m}-k_{m}$ dimensional vector that expresses economic explanatory variables which explain the total factor productivity growth (TFP growth) - our dependent variable;

$\beta_{m}$ - vector that reflects marginal contributions of the explanatory variables;

$\beta_{0}$ - intercept of the regression;

$u_{i}$ - error term.

Table 3 below shows the respective results. The posterior inclusion probabilities (PIPs) expressed the posterior probability that a given regressor forms part of the "true" linear regression model. Table 3 also contains the posterior means (Post.Mean) and posterior standard deviations (Post SD). The posterior means informed us about the extent of the determinant's effect, whereas posterior standard deviation assessed its deviation. We assumed that the "true TFP model" can consist of a base specification and a few additional variables. We should remember that national economies typically show some heterogeneity, meaning that a small number of complementary determinants may contribute to the scope of TFP growth. On the other hand, some of the potential TFP growth determinants may turn out to be substitutes insofar as countries' socio-economic interpretation is concerned. Hence, there is a certain probability that characterises situations when we deal with an early inclusion of a regressor/determinant. 
Table 3. Coefficient results (BMA)

\begin{tabular}{|c|l|c|c|c|c|c|c|}
\hline Var & \multicolumn{1}{|c|}{ Var Name } & Code & PIP & Post.Mean & Post SD & Cond.Pos.Sign & Idx \\
\hline$X_{1}$ & Growth of ICT assets & GICT & 0.959 & -0.121 & 0.0405 & 0.0000 & 1 \\
\hline$X_{2}$ & Human capital growth & HCG & 0.102 & 0.0024 & 0.1272 & 0.5974 & 2 \\
\hline$X_{3}$ & Gurrent education expenditure & CEE & 0.281 & -0.0247 & 0.0600 & 0.0130 & 3 \\
\hline$X_{4}$ & Government expenditure on education & GEE & 0.182 & -0.0039 & 0.0777 & 0.4095 & 4 \\
\hline$X_{5}$ & School enrollment, tertiary & SET & 0.132 & 0.1039 & 0.6665 & 0.8643 & 5 \\
\hline$X_{6}$ & Transport services, commercial exports & TSCE & 0.191 & 0.0070 & 0.0263 & 0.9165 & 6 \\
\hline$X_{7}$ & Transport services, commercial imports & TSCl & 0.241 & -0.0095 & 0.0317 & 0.0868 & 7 \\
\hline$X_{8}$ & Air transport as passengers carried & ATPC & 0.152 & -0.0634 & 1.2896 & 0.3894 & 8 \\
\hline$X_{9}$ & New business density & NBD & 0.327 & -0.0223 & 0.0461 & 0.0376 & 9 \\
\hline$X_{10}$ & R\&D expenditures & RD & 0.191 & 0.0917 & 0.497 & 0.7595 & 10 \\
\hline$X_{11}$ & Researchers in R\&D & RRD & 0.231 & -0.1678 & 0.5718 & 0.1844 & 11 \\
\hline$X_{12}$ & Technicians in R\&D & TRD & 0.129 & -0.0362 & 0.2448 & 0.2325 & 12 \\
\hline$X_{13}$ & Total patent applications & TPA & 0.315 & 0.0586 & 0.1554 & 0.9662 & 13 \\
\hline$X_{14}$ & Trademark applications, total & TA & 0.177 & 0.0245 & 0.2367 & 0.7476 & 14 \\
\hline$X_{15}$ & Quality of trade and transport infrastructure & QTTI & 0.123 & -0.1648 & 0.8634 & 0.1563 & 15 \\
\hline$X_{16}$ & Trade & TRADE & 0.204 & 0.0940 & 0.4870 & 0.794 & 16 \\
\hline$X_{17}$ & FDI net inflows & FDI & 0.175 & -0.0654 & 0.3209 & 0.1371 & 17 \\
\hline$X_{18}$ & Crude rate of net migration & MIG & 0.477 & -0.0290 & 0.0379 & 0.0000 & 18 \\
\hline$X_{19}$ & Competence and quality of logistics services & CQLS & 0.957 & -8.7528 & 3.2009 & 0.0045 & 19 \\
\hline$X_{20}$ & Quality of port infrastructure & QPI & 0.580 & 0.4462 & 0.4863 & 1.0000 & 20 \\
\hline$X_{21}$ & Logistics performance index & LPI & 0.984 & 9.4564 & 3.3889 & 0.9978 & 21 \\
\hline$X_{22}$ & Gini coefficient & GC & 1.000 & 0.5107 & 0.0943 & 1.0000 & 22 \\
\hline & & & 1.000 & -0.5983 & NA & NA & \\
\hline
\end{tabular}

Source: own study.

Table 3 shows the variables and their corresponding statistics. The fourth column "Post.Mean" shows the coefficients averaged across all models, including the ones wherein the variable was not contained (implying that the coefficient is zero in such case). The following covariates exhibited comparatively large positive or negative coefficients and seem to be relevant: Gini coefficient (GC), growth of ICT assets (GICT), competence and quality of logistics services (CQLS), logistics performance index (LPI), quality of port infrastructure (QPI), and crude rate of net migration (MIG). The third column (PIP) shows the importance of variables in explaining the data, which represents posterior inclusion probabilities, i.e. the sum of PMPs for all models wherein a covariate was included. We saw with $100 \%$ certainty that all posterior model mass rested on models that included inequality measured by the Gini coefficient (GC). In turn, growth of ICT assets (GICT) had the PIP of appx. $95.96 \%$, competence and quality of logistics services (CQLS) $-95.73 \%$, logistics performance index (LPI) $-94.83 \%$, quality of port infrastructure (QPI) $-58 \%$, crude rate of net migration (MIG) $47.76 \%$. Other co-variates had corresponding PIP values within the range $10.26-31.56 \%$ and seemed to matter less. The coefficient sign could have also been inferred from the sixth column Cond.Pos.Sign, the "posterior probability of a positive coefficient expected value conditional on inclusion" (Zeugner \& Feldkircher, 2015). Finally, the last column idx denotes the index of the variables' appearance in the data set, which might be useful when sorting the results by PIP values. Considering PIP values, the variables explaining TFP growth can be generally divided into four groups, which are showed in Table 4 below. Distinguishing our regressors by relevance of provided evidence made it easier to assess their reliability in explaining the variability of endogenous variable. Those with the highest PIP value provided the strongest evidence justifying their inclusion in the true regression model that described the variability of the response variable (TFP growth).

In the next step we checked which models actually performed best. To this end, we used a function that expressed binary representations for all included model specifications. Table 5 below shows the results of the top three models. 
Table 4. Division of regressors according to provided evidence

Regressors with strong evidence for which PIP $>0.5$. This group in- The second group are regressors with mecludes variables that exhibit greater posterior inclusion probability com-dium evidence, $I \mathrm{n}$ which $0,5 \geq P I P>$ pared to the priors. In the case of these variables, we may conclude that 0,2 . There are seven such determinants in there is strong evidence justifying their inclusion in the true model. In the case of our TFP gowth analysis, namely our study, we were able to indicate five such variables that belong to the crude rate of net migration (MIG), new group of regressors providing strong evidence in explaining the variabil-business density (NBD), total patent appliity of TFP growth, namely the Gini coefficient (GC), growth of ICT assets cations (TPA), current education expendi(GICT), competence and quality of logistics services (CQLS), logistics per-ture (CEE), transport services - commercial formance index (LPI), and quality of port infrastructure (QPI).

imports (TSCSI), and trade (TRADE).

Regressors with weak evidence $0,2 \geq P I P>0,1$, i.e. those with a rel-Regressors with negligible evidence atively low probability of posterior inclusion compared to priors; alt- $(P I P \leq 0,1$. $)$. Regressors belonging to hough it can be shown that they also explain the variability of our exog-this group provided the weakest evienous variable: TFP growth. In our quantitative TFP growth study, there dence that they were in fact true deterwere 10 such regressors/determinants, i.e. transport services - com- minants of the endogenous variable unmercial exports (TSCSE), R\&D expenditures (RD), government expendi- der investigation. This group provided ture on education (GEE), trademark applications (TA), FDI net inflows little evidence for explaining the TFP (FDI), air transport - passengers carried (ATPC), school enrollment ter-growth. None of the regressors included tiary (SET), technicians in R\&D (TRD), quality of trade and transport in- in the study fell into this particular frastructure (QTTI), and human capital growth (HCG). group.

Source: own study.

Table 5. Top three models

\begin{tabular}{|l|l|l|l|l|}
\hline \multicolumn{1}{|c|}{ Variable } & \multicolumn{1}{|c|}{ Code } & 20001b & $\mathbf{2 0 0 0 0 b}$ & $\mathbf{2 0 0 0 1 f}$ \\
\hline Growth of ICT assets & GICT & 1.0000 & 1.0000 & 1.0000 \\
\hline Human capital growth & HCG & 0.0000 & 0.0000 & 0.0000 \\
\hline Current education expenditure, total & CEE & 0.0000 & 0.0000 & 0.0000 \\
\hline Government expenditure on education & GEE & 0.0000 & 0.0000 & 0.0000 \\
\hline School enrollment, tertiary (\% gross) & SET & 0.0000 & 0.0000 & 0.0000 \\
\hline Transport services (commercial exports) & TSCSE & 0.0000 & 0.0000 & 0.0000 \\
\hline Transport services (commercial imports) & TSCSI & 0.0000 & 0.0000 & 0.0000 \\
\hline Air transport as passengers carried & ATPC & 0.0000 & 0.0000 & 0.0000 \\
\hline New business density & NBD & 0.0000 & 0.0000 & 0.0000 \\
\hline R\&D expenditures (\% of GDP) & RD & 0.0000 & 0.0000 & 0.0000 \\
\hline Researchers in R\&D (per million people) & RRD & 0.0000 & 0.0000 & 0.0000 \\
\hline Technicians in R\&D (per million people) & TRD & 0.0000 & 0.0000 & 0.0000 \\
\hline Total patent applications & TPA & 0.0000 & 0.0000 & 0.0000 \\
\hline Trademark applications, total & TA & 0.0000 & 0.0000 & 0.0000 \\
\hline Quality of trade and transport infrastructure & QTTI & 0.0000 & 0.0000 & 0.0000 \\
\hline Trade (\% of GDP) & TRADE & 0.0000 & 0.0000 & 0.0000 \\
\hline FDI net inflows (\% of GDP) & FDI & 0.0000 & 0.0000 & 0.0000 \\
\hline Crude rate of net migration & MIG & 1.0000 & 0.0000 & 1.0000 \\
\hline Competence and quality of logistics services & CQLS & 1.0000 & 1.0000 & 1.0000 \\
\hline Quality of port Infrastructure & QPI & 0.0000 & 0.0000 & 1.0000 \\
\hline Logistics performance index & LPI & 1.0000 & 1.0000 & 1.0000 \\
\hline Gini coefficient & GC & 1.0000 & 1.0000 & 1.0000 \\
\hline & PMP (MCMC) & 0.2416 & 0.1386 & 0.0780 \\
\hline
\end{tabular}

Source: own study.

Table 5 also shows the posterior model probability for all three models. As the results showed, thebest of the presented models was characterised by a $24.16 \%$ probability of the posterior model and contained five regressors. However, the second best model contains four variables/regressors and had a corresponding PMP of $13.86 \%$. 


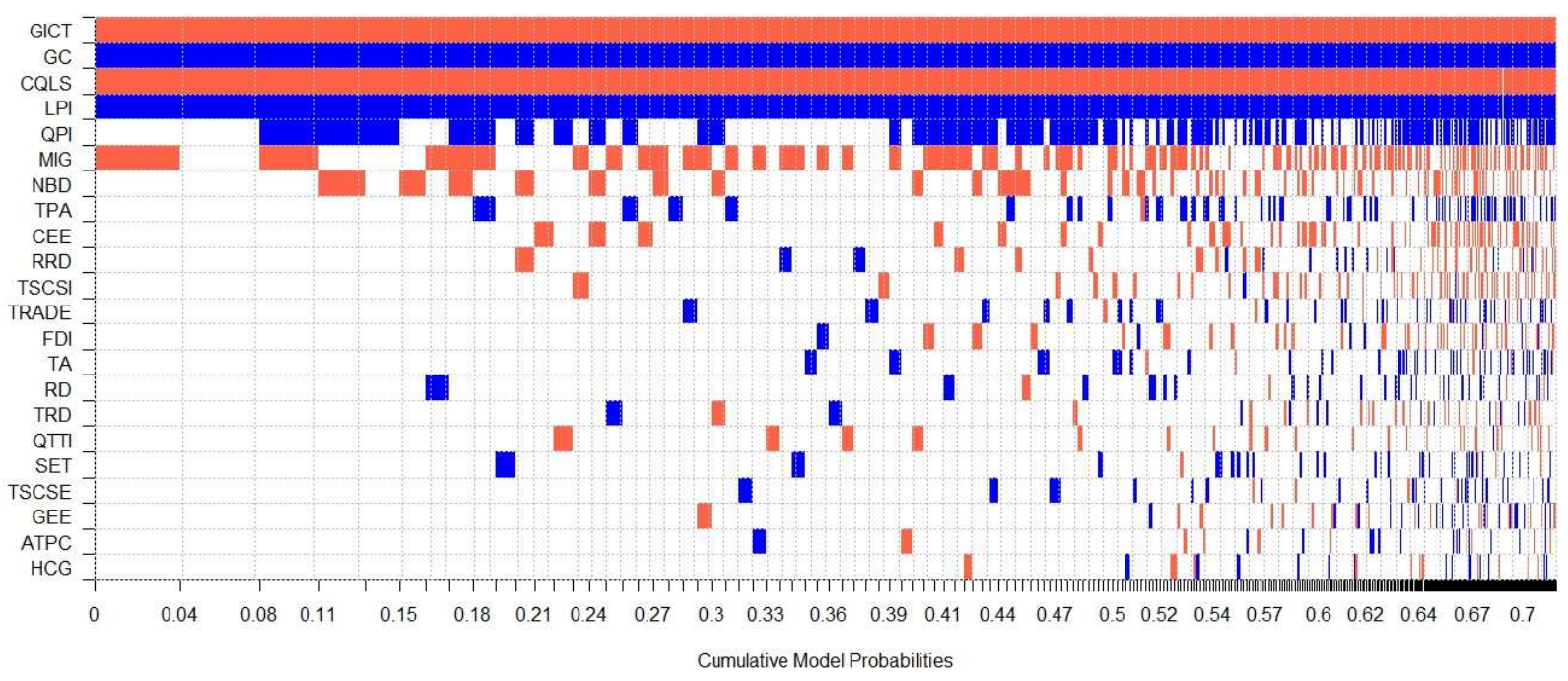

Figure 2. Model inclusion vased on best $\mathbf{5 0 0}$ models Source: own elaboration.

Figure 2 allowed for a more comprehensive model overview. Positive coefficients were shown in blue and negative ones in red. In turn, white colour indicated zero coefficients, meaning that in this case no specific regressors were included in the real model (i.e. non-inclusion). Figure 2 also showed the cumulative probability of the analysed models (i.e. best 500 models) scaled by their PMPs. We could see e.g. which regressors were more frequently incorporated into the models and even whether they had stable coefficient signs. After all, there were cases when they had positive and negative coefficients, depending on the models. This graphical representation of the problem under investigation allowed us to see that the best model contained the following variables: the growth of ICT assets (GICT), Gini coefficient (GC), competence and quality of logistics services (CQLS), logistics performance index, (LPI), and crude rate of net migration (MIG). Furthermore, we saw that the growth of ICT assets (GICT), Gini coefficient (GC), competence and quality of logistics services (CQLS), and logistics performance index (LPI) were incorporated in virtually all models. In contrast, there were variables/regressors that were included rarely, and their coefficient signs changed according to the model, e.g. reserchers in R\&D (RRD) or trade (TRADE).

The PIP column represented posterior inclusion probabilities (PMPs), i.e. the sum of the PMPs for all models in which the variable was included, thus it captured the importance of the variables in explaining the data. If PIP was $100 \%$ - as is the case for the Gini coefficient (GC) variable - it meant that virtually all of the posterior model mass rests on this particular variable. Next in order were the growth of ICT Assets (GICT) with the PIP value of $95.96 \%$, competence and quality of logistics services (CQLS) $-95.73 \%$, logistics performance index (LPI) $-94.83 \%$, and quality of port infrastructure (QPI) $-58 \%$. In turn, the crude rate of net migration (MIG) was present in two out of three top models and had a corresponding PIP of $47.76 \%$.

When considering the inclusion of a number of potential regressors in the real model, we should also analyse the posterior expected model size, i.e. the average number of included regressors. When performing a BMA analysis, we can calculate this posterior statistic, which equals the sum of PIP values, and in our case, it was 8.082. This statistic value actually differed from the expected model size, which was calculated for our model sample based on a specific formula. Keep in mind that when dealing with $2^{K}$ possible regressor combinations, the theoretical value of the common prior model probability is equal to $p\left(M_{\gamma}\right)=2^{-K}$. Moreover, the expected model size is $\sum_{k=0}^{K}\left(\begin{array}{l}K \\ k\end{array}\right) k 2^{-K}=\frac{K}{2}$. Furthermore, note that there are many combinations of possible models of $k_{\gamma}$-size, thus the uniform model prior makes the intermediate model sizes more robust. The latter will be characterised by a model size of $k_{\gamma}=11$ 
with probability that is equal to $\left(\begin{array}{l}22 \\ 11\end{array}\right) 2^{-K}=16.81 \%$. Figure 3 below illustrates the deviation between the posterior model size distribution and the prior expected model size $(K / 2)$.

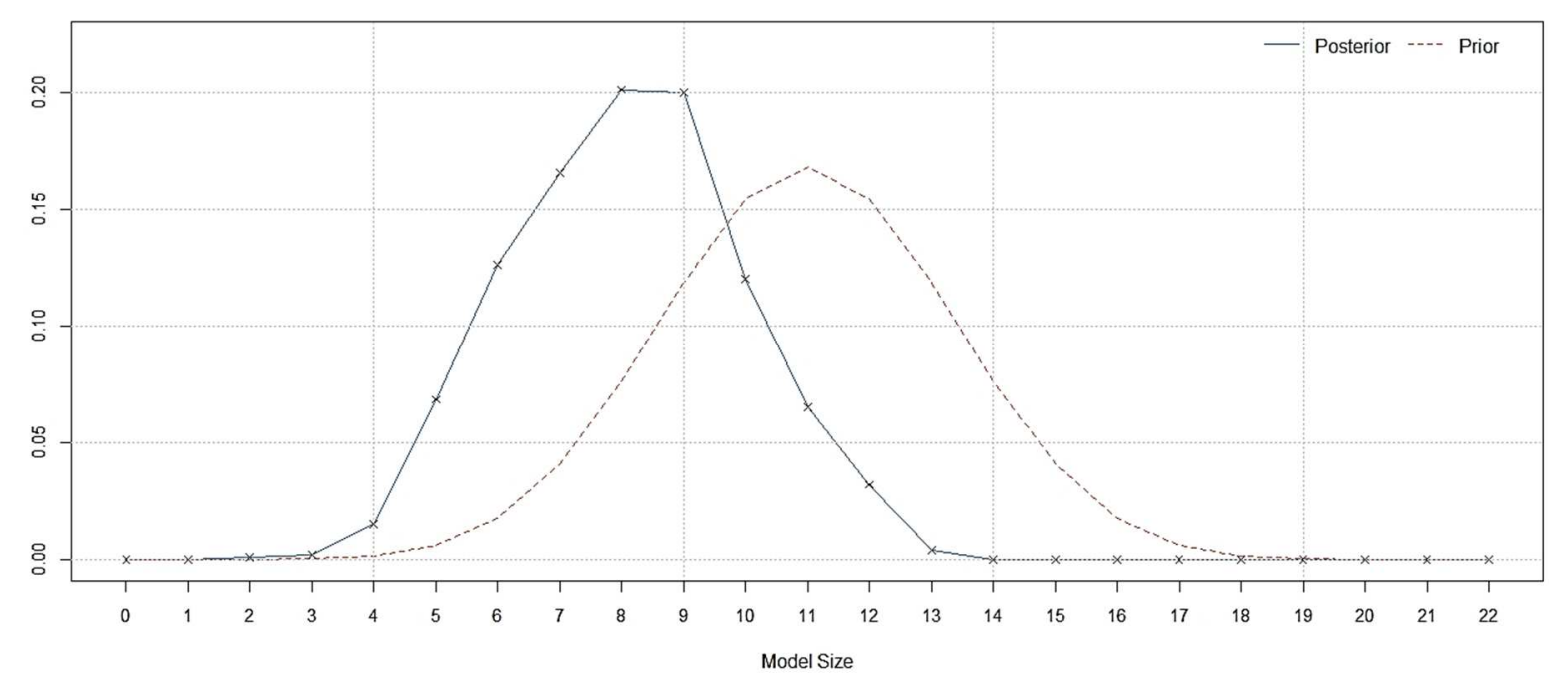

Figure 3. Posterior model size distribution (mean 8.0827)

Source: own elaboration.

Moreover, Figure 3 reveals that the model prior assumes a symmetric distribution around the mean $K / 2=11$, whereas the posterior provides evidence in favour of the models with fewer regressors.

In the study, we wanted to include as many variables as possible, especially those related to mobility factors. In addition to traditional variables (mobility channels) such as FDI and trade, we included variables related to transport infrastructure, logistics, and mobility, associated with e.g. trade and FDI. Such variables were transport services, logistics performance, competence and quality of logistics services, quality of trade and trade infrastructure, quality of port infrastructure, air transport as passengers carried, and net migration. Especially in the context of studies found in the literature, migration can be regarded as a substitute for other mobility factors (e.g. FDI or trade). In light of the HecksherOhlin's theory, migration is a substitute to trade and FDI (Metelski \& Mihi-Ramirez, 2015).

In sum, the study provided supporting evidence for hypotheses $\mathbf{H 1}, \mathbf{H 2}$, and $\mathbf{H 4}$. In contrast, there was no strong evidence supporting hypotheses $\mathbf{H 3}, \mathbf{H 5}$, and $\mathbf{H 6}$. There was medium evidence supportive of hypotheses $\mathbf{H} \mathbf{3}$ and $\mathbf{H} \mathbf{5}$ and weak evidence supportive of hypothesis $\mathbf{H} \mathbf{6}$.

In the context of posterior inclusion probabilities, our study showed that some of the studied TFP growth determinants are indeed meaningful and have corresponding PIP values at a high level, meaning that these variables appear in the majority of models typified as the best of all possible combinations of variables explaining TFP changes: in our case, these variables were 22. In addition to the Gini coefficient and ICT asset growth, we can point to the competence and quality of logistics services (CQLS) with a PIP of $95.73 \%$ and logistics performance index (LPI) with a PIP of $94.83 \%$, the quality of port infrastructure (QPI) with corredponding PIP of $58 \%$, and crude rate of net migration (MIG) with a PIP of $47.76 \%$ - as the most significant variables. This means that the quality of logistics services - along with migration and the associated "brain drain" - are important variables explaining changes in TFP growth. A good example of the impact of logistics and the quality of port infrastructure on productivity growth is provided by Polish ports, which are striving to improve their position in Europe. This is confirmed by the current state of the port of Gdańsk, which is now a regional player, and one of the biggest in the Baltic Sea; all this happened over the last two decades. In the same way, the quality of logistics services is increasing very significantly in Poland. The conclusion is that productivity can be increased not so much through FDI or trade channel but e.g. by improving logistics services and port infrastructure. The same is true for human capital and migration. In this specific example, we see that productivity can be influenced by migration processes, which have 
increased very significantly in the last two decades, as opposed to the improvement in the quality of human capital (which has the lowest corresponding PIP value of merely $10.26 \%$ ).

However, the study has some limitations. Namely, our general assumptions in the construction of the model (concerning priors) based on Zellner's g-priors are very generic, which actually reflects the lack of specific beliefs of researchers concerning the distributions of models' parameters. When performing BMA, it is necessary to set priors both in the model space and in the parameter space within each model (i.e. priors for the regression coefficients and the variance parameter). In this regard, a failure to take an adequate approach when setting a flat prior across all models, may result in significantly different posterior estimates in the PIP for each variable, but also the posterior model size (Eicher, Papageorgiou, \& Raftery, 2011). Since our model has 22 variables, this actually results in $2^{22}=4194304$ possible regression models. It should be emphasised here that these assumptions are very important, since they are the foundation for posterior inclusion probabilities, based on which we formulate the Bayesian inference.

Moreover, let us foreground that we tested whether the data we employed met the CRS assumption. The results of the F-test showed that the data we used (output as a function of capital and labour inputs) exhibit variant returns to scale. In the theoretical part, we emphasised that modern economies operating in the era of industrial revolution 4.0, more and more often benefit from economies of scale, which should be visible in the data, namely in the form of increasing returns to scale (IRS). In other words, modern economies are supposed to be driven by increasing returns to scale. The industrial revolution 4.0 brings with it new forms of economic activities, meaning that some of the output produced may be outside the reportable sphere, e.g. Uber drivers, Youtubers, sellers on Amazon (who may come from different countries), crowdsourcing platforms (e.g. Upwork, Fiverr). In fact, some of the output may be either outside of the reportable space or may be driven by entrepreneurs from countries other than those in which their work (output) is reported. On the one hand, modern digital platforms and technologies enable economies of scale (copying and selling additional digital products is esentially cost-free), and the output itself is in reality probably significantly higher than what we see in the data. All in all, our study provides evidence that supports the importance of the growth of ICT information technologies, which to some extent reflects the problem we have described above. This is actually in line with earlier findings observed by Mokyr (1990) or Hamit-Haggar (2011), e.g. in that technological progress and technological creativity are the driving forces of productivity growth. In our case, this progress is evidenced in the variable ICT assets' growth, which seems to be present across all model space. The ICT assets can be perceived as an important factor influencing productivity growth via the economies of scale channel. On the other hand, it is also worth recalling Diewert and Fox (2008) study, who argue that economic growth is driven by increasing economies of scale rather than technical progress, and that technical progress itself usually turns out to be insignificant.

\section{CONCLUSIONS}

In the article, we focused on the selection of the most robust variables for developing regression models explaining TFP growth. The empirical part of our study relies on the BMA methodology and panel data for 41 developed countries (37 OECD countries, plus Romania, Russia, Croatia, and Cyprus). This framework is rooted both in purely statistical time series analysis of data and in macroeconomic APF theory, which is particularly attractive to those researchers who seek a well-founded framework for modelling aggregate output. Furthermore, since Bayesian model comparison is sensitive to prior distributions, we conducted our study carefully relying on Zellner's g-priors (Zeugner \& Feldkircher, 2015). To make the comparison fully operational, reduce the computational burden, and avoid the possibility of criticism from a purely numerical viewpoint, we restricted ourselves to the simplest classes of $g$ prior distributions. Alongside this, we strived for a reliable review of the literature in the context of the TFP growth by emphasising its importance for the creation of the prosperity of societies. Morevero, we shed light on the importance of BMA models for empirical productivity research, while emphasising the importance of TFP-measured productivity for understanding contemporary economic conditions. Because of the multitude of possible explanatory variables in such regression models (scientists have 
been keen to study productivity for years because - to quote Krugman's classic text (1991) - in the long term everything depends on productivity) and a relative lack of guidance from economic theory as to which variables should be contrasted, we decided to analyse the "robustness" of the results from numerous regression models' specifications. Based on this methodology, we indicated a number of variables that are relevant for modelling productivity growth, classifying them as potential regressors. Moreover, we divided the regressors into four groups due to their posterior inclusion probability (PIP) levels and the resulting strength of the regressions, indicating what the optimal number of variables might be when building such models. We managed to confirm hypotheses $\mathbf{H 1}, \mathbf{H 2}$, and $\mathbf{H 4}$. In contrast, there is no strong evidence supporting the hypotheses $\mathbf{H 3}, \mathbf{H} \mathbf{5}$ and $\mathbf{H 6}$. There is medium evidence supportive of hypotheses $\mathbf{H} \mathbf{3}$ and $\mathbf{H} \mathbf{5}$ and a weak evidence supportive of hypothesis $\mathbf{H 6}$. Such inference is evidenced in the posterior inclusion probabilities (PIPs) showed in Table 3.

With regards to the scientific context, we reviewed the literature that emphasises that a very large part of economic expansion is dependent on the growth of TFP. We indicate a number of determinants that drive TFP growth, e.g. inequality measured by the Gini coefficient, growth of ICT assets, logistics performance, quality of logistics services, quality of port infrastructure, and net migration. Finally, a study based on BMA allows for the selection of TFP regressors but ultimately depends on a sample of the data used for its completion. Therefore, a different selection of countries and period under study will probably yield different results. However, BMA as a research method is gaining more and more popularity because it enables researchers to divide regressors into those that are more relevant and stable and those that show less robustness, thus being an important method for developing economic models.

\section{REFERENCES}

Abramovitz, M. (1956). Resource and output trends in the United States since 1870. In M. Abramovitz (Ed.), Resource and output trends in the United States since 1870 (pp. 1-23). Cambridge, MA: National Bureau of Economic Research.

Angus, M. (1995). Monitoring the World Economy, 1820-1992. Paris: Organization for Economic Cooperation and Development.

Artige L., \& Nicolini R. (2006). Labor Productivity in Europe: Evidence from a sample of regions (Working Paper 2006/08). Liège: CREPP - HEC-ULg.

Ayres, R.U., \& Warr, B. (2005). Accounting for growth: the role of physical work. Structural Change and Economic Dynamics, 16(2), 181-209. https://doi.org/10.1016/j.strueco.2003.10.003

Baier, S.L., Dwyer Jr, G.P., \& Tamura, R. (2006). How important are capital and total factor productivity for economic growth?. Economic Inquiry, 44(1), 23-49. https://doi.org/10.1093/ei/cbj003

Barnett, W. (2004). Dimensions and economics: some problems. The quarterly journal of Austrian ecBaueronomics, 7(1), 95-104. https://doi.org/10.1007/s12113-004-1038-2

Barro, R.J., \& Sala-i-Martin, X. (1995). Economic Growth. New York: McGraw-Hill.

Bauer, P. W. (1990). Decomposing TFP growth in the presence of cost inefficiency, nonconstant returns to scale, and technological progress. Journal of Productivity Analysis, 1(4), 287-299. https://doi.org/10.1007/BF00160047

Benkovskis, K., Fadejeva, L., Stehrer, R., \& Wörz, J. (2012). How important is total factor productivity for growth in Central, Eastern and Southeastern European countries. Focus on European Economic Integration. Vienna: Oesterreichische Nationalbank (Austrian Central Bank).

Blinder A., \& Baumol W. (1993). Economics: Principles and Policy. San Diego: Harcourt Brace Jovanovich.

Bower, J.L., \& Christensen, C.M. (1995). Disruptive technologies: catching the wave. Harvard Business Review, 73(1). https://doi.org/10.1016/0024-6301(95)91075-1

Bradford Delong, J. (2015). Making do with more. Kings Park, NY: Project Syndicate. Retrieved from https://www.project-syndicate.org/commentary/abundance-without-living-standards-growth-by-j--bradford-delong-2015-02?barrier=accesspaylog on September 10, 2020.

Bronzini R., \& Piselli P. (2006). Determinants of Long-run Regional Productivity: The Role of R\&D, Human Capital and Public Infrastructure (Temi di discussione, No.597). Rome: Bank of Italy. 
Burda, M.C., \& Severgnini, B. (2010). Solow residuals without capital stocks (SFB 649, Discussion Paper 2008-040). Berlin: Humboldt-Universität zu Berlin. Retrieved from https://edoc.hu-berlin.de/bitstream/handle/18452/4789/40.pdf?sequence=1 on September 10, 2020

Castiglione, C., \& Infante, D. (2013). ICT as general purpose technologies: a micro-econometric investigation on Italian firms. International Journal of Trade and Global Markets, 6(3), 225-241. https://doi.org/10.1504/IJTGM.2013.054851

Christensen, C.M., \& Overdorf, M. (2000). Meeting the challenge of disruptive change. Harvard business review, 78(2), 66-77. Retrieved from https://hbr.org/2000/03/meeting-the-challenge-of-disruptive-change on October 20, 2020.

Cobb, C.W., \& Douglas, P.H. (1928). A theory of production. The American Economic Review, 18(1), 139-165. Retrieved from https://www.aeaweb.org/aer/top20/18.1.139-165.pdf on September 20, 2020.

Comin D. (2010). Total factor productivity. In: S.N. Durlauf \& L.E. Blume (Eds.), Economic Growth. The New Palgrave Economics Collection (pp. 260-263). London: Palgrave Macmillan. https://doi.org/10.1057/9780230280823_32

Crispolti, V., \& Marconi, D. (2005). Technology transfer and economic growth in developing countries: an econometric analysis (No. 564). Rome: Bank of Italy.

Danquah, M., Moral-Benito, E., \& Ouattara, B. (2014). TFP growth and its determinants: a model averaging approach. Empirical Economics, 47(1), 227-251. https://doi.org/10.1007/s00181-013-0737-y

David, P.A. (2000). Understanding digital technology's evolution and the path of measured productivity growth: present and future in the mirror of the past. Understanding the digital economy: data, tools, and research. Cambridge, MA: MIT Press.

Decker, C.S., Thompson, E.C., \& Wohar, M.E. (2009). Determinants of State Labor Productivity: The Changing Role of Density. Journal of Regional Analysis \& Policy, 39(1), 1-10. Retrieved from: https://business.unl.edu/research/bureau-of-business-research/academic-research/documents/thompson/state-labor.pdf on October 25, 2020.

Denison, E. (2005). Trends in American economic growth, 1929-1982. Washington, DC: Brookings Institution.

Diewert, W.E., \& Nakamura, A.O. (2007). The measurement of productivity for nations. Handbook of econometrics, 6, 4501-4586. https://doi.org/10.1016/S1573-4412(07)06066-7

Diewert, W. E., \& Fox, K. J. (2008). On the estimation of returns to scale, technical progress and monopolistic markups. Journal of Econometrics, 145(1-2), 174-193. Retrieved from https://ideas.repec.org/a/eee/econom/v145y2008i1-2p174-193.html on April 20, 2021.

Di Giacinto, V., \& Nuzzo, G. (2005). Explaining Labour Productivity Differentials on Italian Regions. Rome: Bank of Italy (Economic Research Unit).

Easterly, W., \& Levine, R. (2002). It's not factor accumulation: stylized facts and growth models. Santiago: Banco Central de Chile.

Eicher, T.S., Papageorgiou, C., \& Raftery, A. E. (2011). Default priors and predictive performance in Bayesian model averaging, with application to growth determinants. Journal of Applied Econometrics, 26(1), 30-55. https://doi.org/10.1002/jae.1112

Engelbrecht, H.J. (2002). Human capital and international knowledge spillovers in TFP growth of a sample of developing countries: an exploration of alternative approaches. Applied Economics, 34(7), 831-841. https://doi.org/10.1080/00036840110061947

Espoir, D.K., \& Ngepah, N. (2020). The effects of inequality on total factor productivity across districts in South Africa: a spatial econometric analysis. Geojournal, 1.

https://doi.org/10.1007/s10708-020-10215-2

Färe, R., Grosskopf, S., Norris, M., \& Zhang, Z. (1994). Productivity growth, technical progress, and efficiency change in industrialized countries. The American economic review, 84(1), 66-83. Retrieved from https://www.jstor.org/stable/2117971 on April 10, 2021

Felipe, J., \& McCombie, J.S. (2014). The aggregate production function:'Not even wrong'. Review of Political Economy, 26(1), 60-84. https://doi.org/10.1080/09538259.2013.874192

Fernald, J. (2014). A quarterly, utilization-adjusted series on total factor productivity (Working Paper 2012-19). San Francisco: Federal Reserve Bank of San Francisco. https://doi.org/10.24148/wp2012-19

Fernandez, C., Ley, E., \& Steel, M.F. (2001). Model uncertainty in cross-country growth regressions. Journal of Applied Econometrics, 16(5), 563-576. https://doi.org/10.1002/jae.623 
Fragoso, T.M., Bertoli, W., \& Louzada, F. (2018). Bayesian model averaging: A systematic review and conceptual classification. International Statistical Review, 86(1), 1-28. https://doi.org/10.1111/insr.12243

Frascati, P. (2002). The Measurement of Scientific and Technical Activities. Standard Practice for Surveys of Research and Experimental Development. Paris: OECD.

Frantzen, D. (2000). R\&D, human capital and international technology spillovers: a cross-country analysis. Scandinavian Journal of Economics, 102(1), 57-75.

https://doi.org/10.1111/1467-9442.00184

Fukao, K., \& Miyagawa, T. (2007). Productivity in Japan, the US, and the major EU economies: Is Japan falling behind?. Tokyo: The Research Institute of Economy, Trade and Industry (RIETI).

Gordon, R.J. (2017). The rise and fall of American growth: The US standard of living since the civil war. Princeton, NJ: Princeton University Press.

Grossman, G.M., \& Helpman, E. (1991). Innovation and growth in the global economy. Cambridge: MIT press.

Growiec, J. (2008). A new class of production functions and an argument against purely labor-augmenting technical change. International Journal of Economic Theory, 4(4), 483-502. https://doi.org/10.1111/j.17427363.2008.00090.x

Growiec, J. (2013). A microfoundation for normalized CES production functions with factor-augmenting technical change. Journal of Economic Dynamics and Control, 37(11), 2336-2350. https://doi.org/10.1016/j.jedc.2013.06.006

Hamit-Haggar, M. (2011). TFP growth, technological progress and efficiencies change. International Journal of Productivity and Performance Management, 40(4), 360-371. https://doi.org/10.1108/17410401111123535

Hoeting, J.A., Madigan, D., Raftery, A.E., \& Volinsky, C.T. (1999). Bayesian model averaging: a tutorial. Statistical science, 14(4), 382-401. Retrieved from https://www.jstor.org/stable/2676803 on March 20, 2021.

Hung, J., Salomon, M., \& Sowerby, S. (2004). International trade and US productivity. Research in International Business and Finance, 18(1), 1-25. Retrieved from https://ideas.repec.org/a/eee/riibaf/v18y2004i1p125.html on March 25, 2021.

Isaksson, A. (2007). Determinants of total factor productivity: a literature review (Research and Statistics Staff Working Paper 2/2007). Vienna: United Nations Industrial Development Organization (UNIDO).

Jarmołowicz, W., \& Kuźmar, S. (2014). Efektywność gospodarowania zasobami pracy w regionie na przykładzie województwa wielkopolskiego w latach 2000-2012. Studia i Prace WNEiZ US, 35(2).

Retrieved from http://yadda.icm.edu.pl/yadda/element/bwmeta1.element.ekon-element-000171316367 on March 30, 2021.

Jones, C.I. (1997). On the evolution of the world income distribution. Journal of Economic Perspectives, 11(3), 1936. https://doi.org/10.1257/jep.11.3.19

Jones, C.I. (2005). The shape of production functions and the direction of technical change. The Quarterly Journal of Economics, 120(2), 517-549. https://doi.org/10.1093/qje/120.2.517

Jorgenson, D.W., \& K.M. Vu. (2018). Total Factor Productivity and the Sources of Singapore's Economic Growth: Measurement, Insights, and Consequences. In D. Kusum Das (Ed.), Productivity Dynamics in Emerging and Industrialized Countries (pp. 275-312). London: Routledge.

Kendrick, J.W. (1961). Front matter, productivity trends in the United States. In J.W Kendrick \& M.R. Pech (Eds.), Productivity trends in the United States. Princeton, NJ: Princeton University Press.

Klenow, P.J. (1998). Ideas versus rival human capital: Industry evidence on growth models. Journal of Monetary Economics, 42(1), 3-23. https://doi.org/10.1016/S0304-3932(98)00010-5

Klenow, P.J., \& Rodriguez-Clare, A. (1997). The neoclassical revival in growth economics: Has it gone too far?. NBER macroeconomics annual, 12, 73-103. https://doi.org/10.1086/654324

Koop, G., Osiewalski, J., \& Steel, M. F. (1999). The components of output growth: A stochastic frontier analysis. Oxford Bulletin of Economics and Statistics, 61(4), 455-487. https://doi.org/10.1111/1468-0084.00139

Krugman P. (1990). The Age of Diminished Expectations. London: MIT Press.

Krugman, P. (1991). Endogenous innovation, international trade and growth. Rethinking international trade. London: MIT Press. https://doi.org/10.7551/mitpress/5933.001.0001 
Liu, B.L., Wu, P., \& Liu, Y.H. (2010). Transportation infrastructure and the increase in TFP in China: spatial econometric analysis on provincial panel data. China industrial economics, 3, 54-64. Retrieved from https://en.cnki.com.cn/Article_en/CJFDTotal-GGYY201003009.htm on November 10, 2020.

Makieła, K. (2014). Bayesian stochastic frontier analysis of economic growth and productivity change in the EU, USA, Japan and Switzerland. Central European Journal of Economic Modelling and Econometrics, 6(3), 193216. https://doi.org/10.24425/cejeme.2014.119239

Makieła, K., \& Ouattara, B. (2018). Foreign direct investment and economic growth: Exploring the transmission channels. Economic Modelling, 72, 296-305. https://doi.org/10.1016/j.econmod.2018.02.007

Makieła, K., Wojciechowski, L., \& Wach, K. (2021). Effectiveness of FDI, technological gap and sectoral level productivity in the Visegrad Group. Technological and Economic Development of Economy, 27(1), 149-174. https://doi.org/10.3846/tede.2020.14017

Mankiw, N.G., Romer, D., \& Weil, D.N. (1992). A contribution to the empirics of economic growth. The quarterly journal of economics, 107(2), 407-437. https://doi.org/10.2307/2118477

Manuelli, R.E., \& Seshadri, A. (2014). Human capital and the wealth of nations. American economic review, 104(9), 2736-62. http://dx.doi.org/10.1257/aer.104.9.2736

Markusen, J.R. (1983). Factor Movements and Commodity Trade as Complements. Journal of International Economics, 14(3/4), 341-356. http://dx.doi.org/10.1016/0022-1996(83)90009-0

Metelski, D., \& Mihi-Ramirez, A. (2015). The economic impact of remittances and foreign trade on migration. GrangerCausality approach. Engineering Economics, 26(4), 364-372. http://dx.doi.org/10.5755/j01.ee.26.4.12464

Mokyr, J. (1990). The Lever of Riches: Technological Creativity and Economic Progress. Oxford: Oxford University Press, 31-56. https://doi.org/10.1093/acprof:oso/9780195074772.001.0001

Natividad, G. (2014). Integration and Productivity: Satellite-Tracked Evidence. Management Science, 60(7), 16981718. https://doi.org/10.1287/mnsc.2013.1833

O'Mahony, M., \& Vecchi, M. (2003). Is there an ICT impact on TFP? A heterogeneous dynamic panel approach. London: National Institute of Economic and Social Research (NIESR).

OECD (2001). Measuring Productivity. Measurement of Aggregate and Industry-Level Productivity Growth. Paris: OECD Publications.

Osiewalski, J., Wróblewska, J., \& Makieła, K. (2020). Bayesian comparison of production function-based and timeseries GDP models. Empirical Economics, 58(3), 1355-1380. https://doi.org/10.1007/s00181-018-1575-8

Parente, S.L., \& Prescott, E.C. (2002). Barriers to riches. Cambridge, MA: MIT Press.

Pietrucha, J., \& Żelazny, R. (2020). TFP spillover effects via trade and FDI channels. Economic researchEkonomska istraživanja, 33(1), 2509-2525. https:/doi.org/10.1080/1331677X.2019.1629327

Porter M., Ketels Ch. (2003). UK Competitiveness: Moving to the Next Stage. Boston, MA: Harvard Business School.

Prescott, E.C. (1998). Lawrence R. Klein lecture 1997: Needed: A theory of total factor productivity. International Economic Review, 39(3), 525-551. https://doi.org/10.2307/2527389

Raftery, A.E., Madigan, D., \& Hoeting, J.A. (1997). Bayesian model averaging for linear regression models. Journal of the American Statistical Association, 92(437), 179-191. https://doi.org/10.1080/01621459.1997.10473615

Romer, P.M. (1990). Endogenous technological change. Journal of political Economy, 98(5/2), 71-102. https://doi.org/10.3386/w3210

Sala-i-Martin, X., Doppelhofer, G., \& Miller, R.I. (2004). Determinants of long-term growth: A Bayesian averaging of classical estimates (BACE) approach. American economic review, 94(4), 813-835. https://doi.org/10.1257/0002828042002570

Samuelson P.A., \& Nordhaus W.D. (2012). Ekonomia. Poznań: Rebis.

Shaikh, A. (1974). Laws of production and laws of algebra: the humbug production function. The Review of Economics and Statistics, 56(1), 115-120. https://doi.org/10.2307/1927538

Schiff, M. (1994). How trade, aid and remittances affect international migration (Working Paper Series 1376). Washington, D.C.: The World Bank.

Schreyer, P. (2001). The OECD productivity manual: a guide to the measurement of industry-level and aggregate productivity. International Productivity Monitor, 2(2), 37-51. Retrieved from https://ideas.repec.org/a/sls/ipmsls/v2y20015.html on April 13, 2021.

Schwab, K. (2016). The fourth industrial revolution (First US edition). New York: Crown Business. 
Schwab, K., \& Samans, R. (2016). The future of jobs: Employment, skills and workforce strategy for the fourth industrial revolution. Cologny: World Economic Forum

Senhadji, A. (2000). Sources of economic growth: An extensive growth accounting exercise. IMF staff papers, 47(1), 129-157. https://doi.org/10.2307/3867628

Sequeira, T.N., Santos, M., \& Ferreira-Lopes, A. (2017). Income inequality, TFP, and human capital. Economic Record, 93(300), 89-111. https://doi.org/10.1111/1475-4932.12316

Shackleton, R. (2013). Total factor productivity growth in historical perspective (Working paper 2013-01). Washington: Congressional Budget Office.

Sickles, R.C., \& Zelenyuk, V. (2019). Measurement of productivity and efficiency. Cambridge: Cambridge Univesity Press. https://doi.org/10.1017/9781139565981

Simon, H. A. (1979). On parsimonious explanations of production relations. The Scandinavian Journal of Economics, 459-474. https://doi.org/10.2307/3439661

Sobieraj, J. (2019). The Fourth Industrial Revolution. Madrid: Aurum Universitas (Hespéride). https://doi.org/10.5281/zenodo.4072721

Sobieraj, J., Metelski, D. (2021). Application of the Bayesian New Keynesian DSGE Model to PolishMacroeconomic Data. Engineering Economics, 32(2). https://doi.org/10.5755/j01.ee.32.2.27214

Solow, R.M. (1956). A contribution to the theory of economic growth. The quarterly journal of economics, 70(1), 65-94. https://doi.org/10.2307/1884513

Solow, R.M. (1957). Technical change and the aggregate production function. The review of Eco-nomics and Statistics, 39(3), 312-320. https://doi.org/10.2307/1926047

Swan, T.W. (1956). Economic growth and capital accumulation. Economic record, 32(2), 334-361. https://doi.org/10.1111/j.1475-4932.1956.tb00434.x

Temple, J. (2006). Aggregate production functions and growth economics. International Review of Applied Economics, 20(3), 301-317. https://doi.org/10.1080/02692170600736052

Ten Raa, T., \& Shestalova, V. (2011). The Solow residual, Domar aggregation, and inefficiency: a synthesis of TFP measures. Journal of Productivity Analysis, 36(1), 71-77. https://doi.org/10.1007/s11123-010-0205-z

Watanabe, C., \& Ilmola, L. (2018). Digitalization of global economy and public sector funding. Reports on scientific computing and optimization. Retrieved from https://jyx.jyu.fi/bitstream/handle/123456789/60723/978951-39-7659-0.pdf?sequence=1 on Novermber 10, 2020.

Xu, B., \& Wang, J. (1999). Capital goods trade and R\&D spillovers in the OECD. Canadian Journal of Economics, 32, 1258-1274. https://doi.org/10.2307/136481

Zellner, A. (1986) On Assessing Prior Distributions and Bayesian Regression Analysis with g-Prior Distributions. In: P. Goel \& A. Zellner (Eds.), Bayesian Inference and Decision Techniques: Essays in Honor of Bruno de Finetti (pp. 233-243). New York: Elsevier Science Publishers.

Zeugner, S., \& Feldkircher, M. (2015). Bayesian model averaging employing fixed and flexible priors: The BMS package for R. Journal of Statistical Software, 68(4), 1-37. http://dx.doi.org/10.18637/jss.v068.i04 


\section{Authors}

Contribution share of authors is equal and amounted to $50 \%$ for each of them.

\section{Janusz Sobieraj}

Assistant Professor in the Department of Building Engineering, Faculty of Civil Engineering at the Warsaw University of Technology. $\mathrm{He}$ is a civil engineer with a degree from the Warsaw University of Technology and holds a PhD in economic sciences in the field of management sciences from the Department of Computer Science and Management of the Wrocław University of Technology. He is an author of several books on construction management, strategic management, and industrial revolution 4.0. His research interests are primarily in the areas of construction management, entrepreneurship, applied economics, mobility factors, productivity, organisations and management, and technologies.

Correspondence to: Janusz Sobieraj, PhD, Department of Building Engineering, Faculty of Civil Engineering, Warsaw University of Technology, Poland, e-mail: jsob@il.pw.edu.pl

ORCID (1) http://orcid.org/0000-0002-0819-7384

\section{Dominik Metelski}

Research Assistant in the Department of Spanish and International Economics at the University of Granada (Spain). He is an economist with a degree from the University of Warsaw and holds a PhD in the field of economic sciences from the Department of International Economics of the University of Granada, under the Programme of Studies on Advanced Techniques in Financial and Commercial Planning, Management, and Control. His research interests are primarily related to such topics as productivity, migration, and issues in the areas of entrepreneurship, innovation, real options, and financial markets, with particular emphasis on companies' valuations, portfolio management, and financial options.

Correspondence to: Dominik Metelski, PhD, Department of Spanish and International Economics at University of Granada, Spain, e-mail: dmetelski@ugr.es

ORCID (1) http://orcid.org/0000-0003-0195-0342

\section{Acknowledgements and Financial Disclosure}

This article constitutes a research development study that was funded by the authors themselves. They received no research subsidy for the preparation of the article. The authors thank previous researchers for their hard work and Entrepreneurial Business and Economics Review for accepting their article for publication.

\section{Conflict of Interest}

The authors declare that the research was conducted in the absence of any commercial or financial relationships that could be construed as a potential conflict of interest.

\section{Copyright and License}

This article is published under the terms of the Creative Commons

Attribution - NoDerivs (CC BY-ND 4.0) License

http://creativecommons.org/licenses/by-nd/4.0/ 
